CHAPTER 26

\title{
Antler Frontlets
}

\section{Ben Elliott, Becky Knight and Aimée Little}

\section{Introduction}

The striking image of the Star Carr antler frontlets initially excavated by Clark (1954), and their implications for both Mesolithic cosmology and hunting practices, has fascinated archaeologists since their original discovery and led to their elevated status as iconic pieces of Early Mesolithic material culture (Lane and Schadla-Hall 2004). They feature in major narratives of World Prehistory (e.g. Mithen 2011; Scarre 2013) and, until recently, were considered a rare insight into Mesolithic ritual behaviour (Clark 1972). The 2004-2015 excavations at Star Carr recovered an assemblage of 12 humanly modified red deer frontlets. These include male and female animals, and also examples of modified crania with shed antlers. Seven (58\%) are concentrated around Clark's area, whilst the rest are distributed across the wetland areas of the site.

This chapter will review Clark's original analysis of the Star Carr frontlets, before presenting the results of the zooarchaeological, traceological and microwear analysis undertaken on these new finds. This will be followed by a discussion of the technological implications that the findings of our analysis, in relation to recent experimental work carried out at the York Experimental Archaeology Research (YEAR) Centre and current understandings of this artefact type across Europe. Finally, our interpretation of these artefacts, based on the analysis presented, will be discussed.

\section{Clark's analysis}

Deemed some of his most spectacular finds, Clark $(1954,168)$ excavated 21 'stag frontlets having still in place portions of antler worked in a special manner', which he noted as sharing five key characteristics:

1. Beams reduced by removal of at least $75 \%$ of their circumference, and the spongy tissue removed to leave only the compactor.

2. The tines were similarly reduced, with $50 \%$ of the circumference being removed.

3. The interior aspect of the burr is removed.

How to cite this book chapter:

Elliott, B., Knight, B. and Little, A. 2018. Antler Frontlets. In: Milner, N., Conneller, C. and Taylor, B. (eds.) Star Carr Volume 2: Studies in Technology, Subsistence and Environment, pp. 297-333. York: White Rose University Press. DOI: https:// doi.org/10.22599/book2.1. Licence: CC BY-NC 4.0 
4. The exterior aspect of the burr is retained.

5. When represented, the parietal bones are always perforated.

The technical terms used by Clark are illustrated within Figure 26.1. However, despite this seemingly clear definition within this group of artefacts, there existed significant variation relating to the levels to which the parietal and frontal bones had been reduced, the extent of the antler retained (including the number of tines still apparent), the area of burr removed, the reduction and smoothing of the rim and interior of the braincase, and the presence and quantity of perforations.

This variation led Clark to define three distinct groups: Class A frontlets (retaining the external aspect of the beam), Class B1 (retaining the posterior aspect of the beam) and Class B2 (retaining the postero-external aspect of the beam). Clark interpreted the worked stag frontlets as headdresses, based on the hypothesis that the perforations and supraorbital fossa (when present) could have been used to attach webbing or strapping, that the reduction of the antlers would have lightened the artefacts considerably, and that the attention paid to the regularisation and smoothing of the rim and interior of the brain case would have made them more suitable for wearing on the head.

He suggested two alternative hypotheses for wearing these red deer headdresses: either as part of a hunting disguise which allowed people to either attract deer or approach them at very close quarters, or as part of a ritualised costume for shamanic ceremonies. Both suggestions are supported by several ethnographic sources which feature hunter-gatherer groups from North America and Siberia who create deer headdresses for use in each context (Witsen and Boddaert 1705; Boas 1835; Birket-Smith 1929).

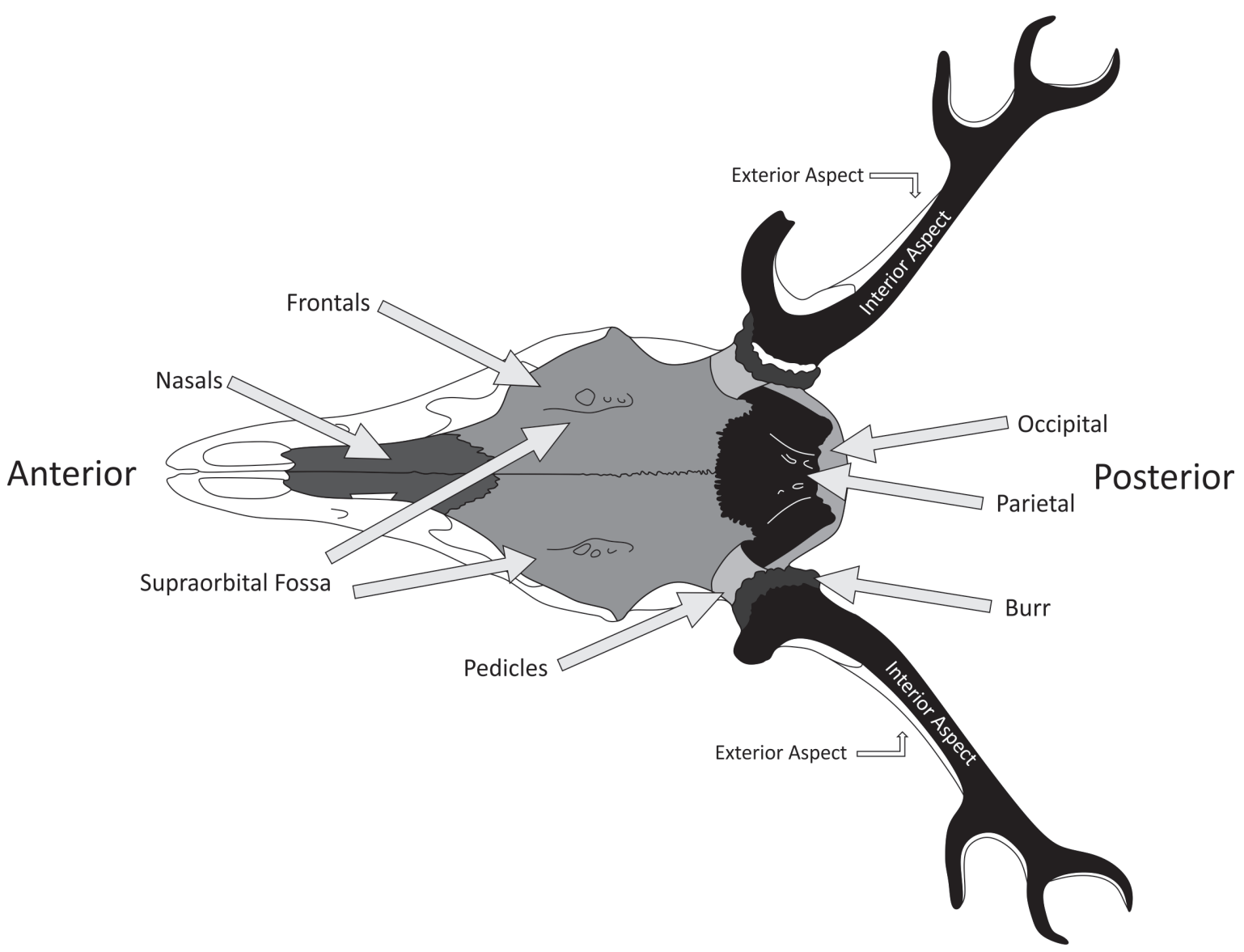

Figure 26.1: Schematic diagram of red deer cranium with key terms highlighted (Copyright Ben Elliott, CC BY-NC 4.0). 


\section{Methods}

Following excavation, the frontlets were analysed from a zooarchaeological and traceological perspective, and the potential for microwear and residue analysis assessed (Chapter 15). They were then illustrated and conserved before being modelled through structure-from-motion techniques. The exceptions to this were frontlet $<103625>$, which was laser scanned prior to conservation, and $<113901>$, which was recorded in situ, illustrated and then immediately conserved due to its poor condition. At the time of writing $<103625>$ was still in conservation and could not be photographed.

\section{Spatial distribution}

The deposition of worked red deer antler frontlets occurs across several different phases of the site's occupation, and varies in intensity and environmental context (Figure 26.2; Table 26.1). The earliest frontlets to be deposited at the site have been recovered from the detrital wood scatter. The Bayesian dating model suggests that the deposition of both $<99528>$ and $<103625>$ took place between 9315-9245 cal BC (start wood scatter; Figure 17.20) and 9115-8915 cal BC (end wood scatter; Figure 17.20) (95\% probability) or probably between 9290-9255 cal BC and 9095-9005 cal BC (68\% probability).

A much more intensive episode of frontlet deposition occurred between 8885-8775 cal BC (start Clark area; Figure 17.20) and $8815-8715$ cal BC (95\% probability) (end Clark area; Figure 17.20), probably between $8840-$ $8790 \mathrm{cal} \mathrm{BC}$ and $8800-8750 \mathrm{cal} \mathrm{BC}$ (68\% probability). This phase of occupation also encompassed the deposition of the assemblage excavated by Clark and as such includes the 21 complete or partial frontlets recorded in his excavations, along with the seven recovered from this area of the site more recently. This small cluster includes male and female frontlets, individuals with shed antlers, individuals with heavily reduced antlers,

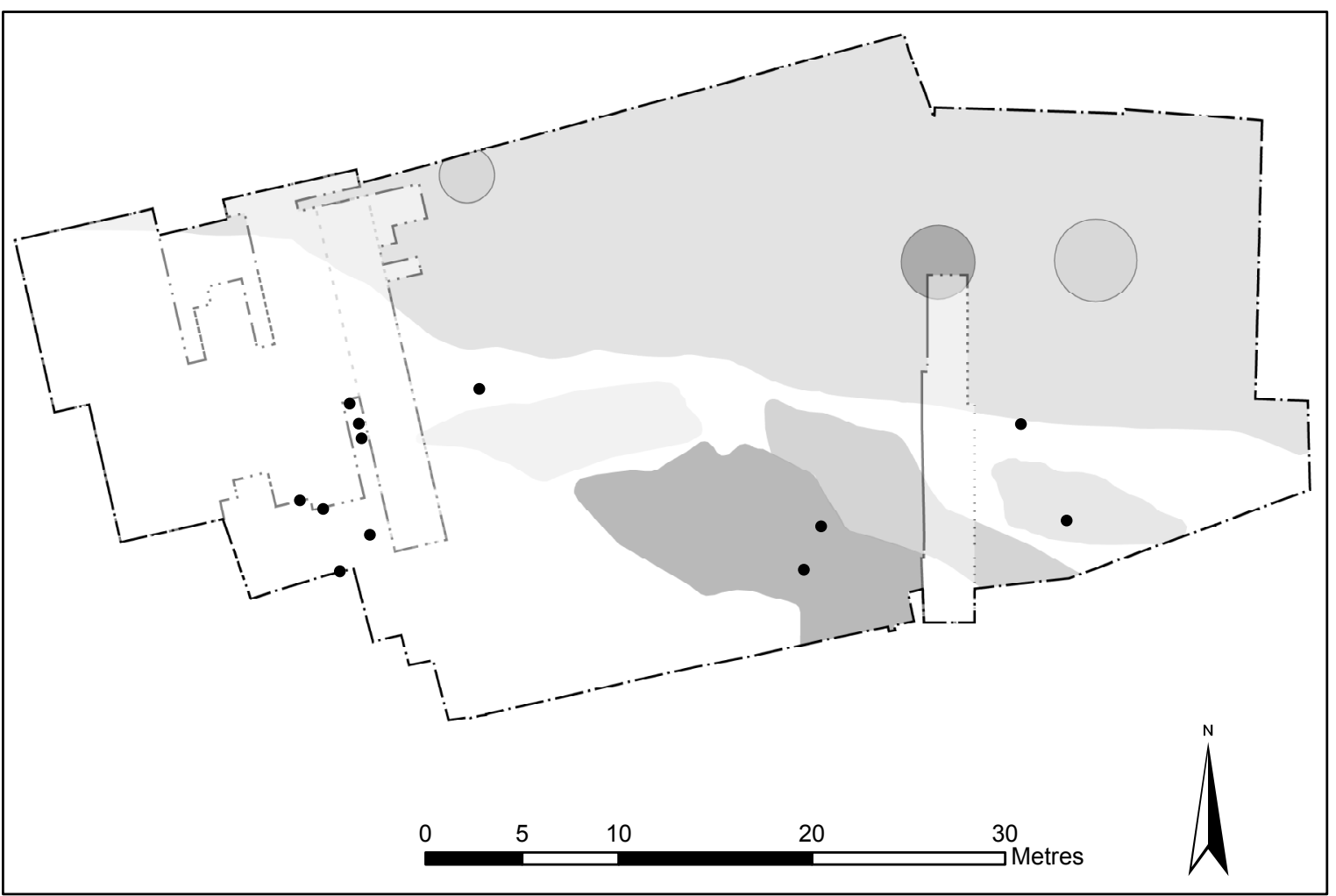

Figure 26.2: Spatial plot of the antler frontlets (Copyright Star Carr Project, CC BY-NC 4.0). 


\begin{tabular}{|c|c|c|c|c|c|c|}
\hline Finds number & Area & Context & Braincase reduced? & Sex & Shed? & Type \\
\hline 95870 & Clark backfill & Clark backfill & $\mathrm{Y}$ & M & Unshed & B1 \\
\hline 99528 & Detrital wood scatter & 312 & $\mathrm{Y}$ & M & Unshed & A \\
\hline 103625 & Detrital wood scatter & 317 & $\mathrm{Y}$ & M & Unshed & B2 \\
\hline 113901 & Woodpeat/ lake edge & 310 & $\mathrm{Y}$ & M & Unshed & $\mathrm{A}$ \\
\hline 113732 & Eastern platform & 312 & $\mathrm{Y}$ & M & Unshed & A \\
\hline 114937 & Clark's area & 312 & $\mathrm{Y}$ & M & Unshed & A \\
\hline 115876 & Clark's area & 312 & $\mathrm{Y}$ & M & Unshed & B2 \\
\hline 116020 & Clark's area & 312 & $\mathrm{~N}$ & M & Shed & $\mathrm{N} / \mathrm{a}$ \\
\hline 116601 & Clark's area & 317 & $\mathrm{Y}$ & M & Shed & $\mathrm{N} / \mathrm{a}$ \\
\hline 116862 & Clark's area & 312 & $\mathrm{Y}$ & M & Unshed & $\mathrm{N} / \mathrm{a}$ \\
\hline 116888 & Clark's area & 317 & $\mathrm{Y}$ & M & Shed & $\mathrm{N} / \mathrm{a}$ \\
\hline 117803 & Clark's area & 312 & $\mathrm{~N}$ & $\mathrm{~F}$ & N/a & $\mathrm{N} / \mathrm{a}$ \\
\hline
\end{tabular}

Table 26.1: Details of the frontlets found during the 2004-2015 excavations.

individuals with significant portions of the beams and tines intact and (if Clark's data is considered) individual artefacts which had been perforated.

Frontlet $<113732>$ was excavated from the area of the eastern platform, although directly relating the dates from the construction of this platform and the production and deposition of this particular artefact is difficult on stratigraphic grounds.

Finally the poorly preserved and heavily flattened frontlet $<113901>$ was excavated upslope, within a peat-forming environment at the interface between reed swamp and wood fen environments (see Chapter 19). The drier, degraded nature of these deposits make them both difficult to date and also prevent the preservation of organic material necessary to accurately define the local environmental conditions. As such, it is difficult to place this particular artefact within the broader site sequence.

\section{Analysis}

$<\mathbf{9 5 8 7 0}>$ (Figure 26.3): A very poorly preserved left-sided pedicle, burr region and c. 20\% of the lower beam circumference. The spur of compactor situated at the posterior aspect, qualifies this as a Class B1 frontlet under Clark's original system, and it is the presence of this $20 \%$ of posterior compactor which led to this piece being identified as a fragmented frontlet and not a piece of groove-and-splinter debitage. The lack of any attached frontal or parietal bone make it impossible to ascertain if the original artefact was perforated. Although the surface detail is lacking, the longitudinally aligned edges of the remaining beam compactor tissue suggest grooving, and the lack of spongy tissue across the base of the antler is also indicative of the scooping which Clark notes for other frontlets from Star Carr. The interior burr is intact, although the poor preservation makes it impossible to assess the state of the exterior burr at the time of deposition. Although clearly not representing a full frontlet, this specimen has firm parallels with the fragmented finds that Clark notes and records as AF19-21.

Figure 26.3 (page 301): Frontlets $<95870>$ and $<113732>$ (Copyright Chloe Watson, CC BY-NC 4.0). 


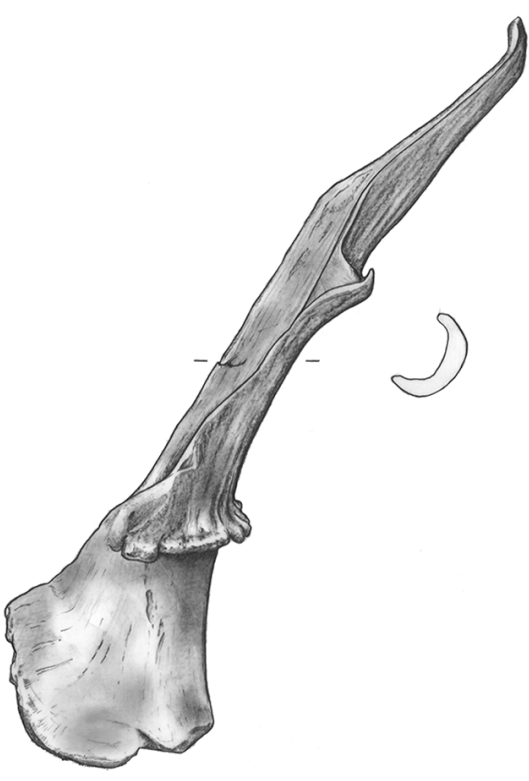

$0 . \quad .50 \mathrm{~mm}$

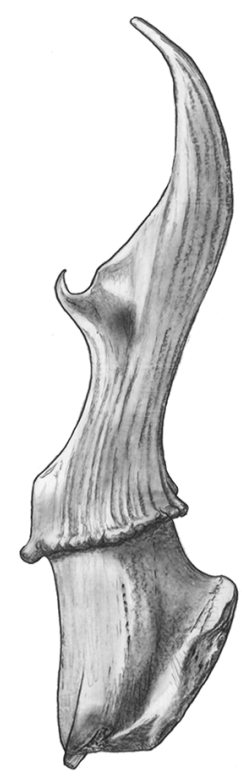

Red deer Frontlet

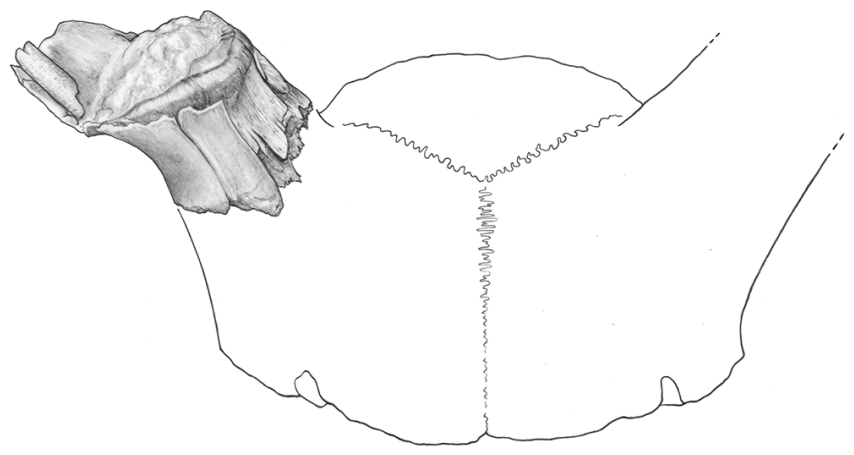

$0 . \quad .50 \mathrm{~mm}$

Red deer Frontlet SCI 395870 


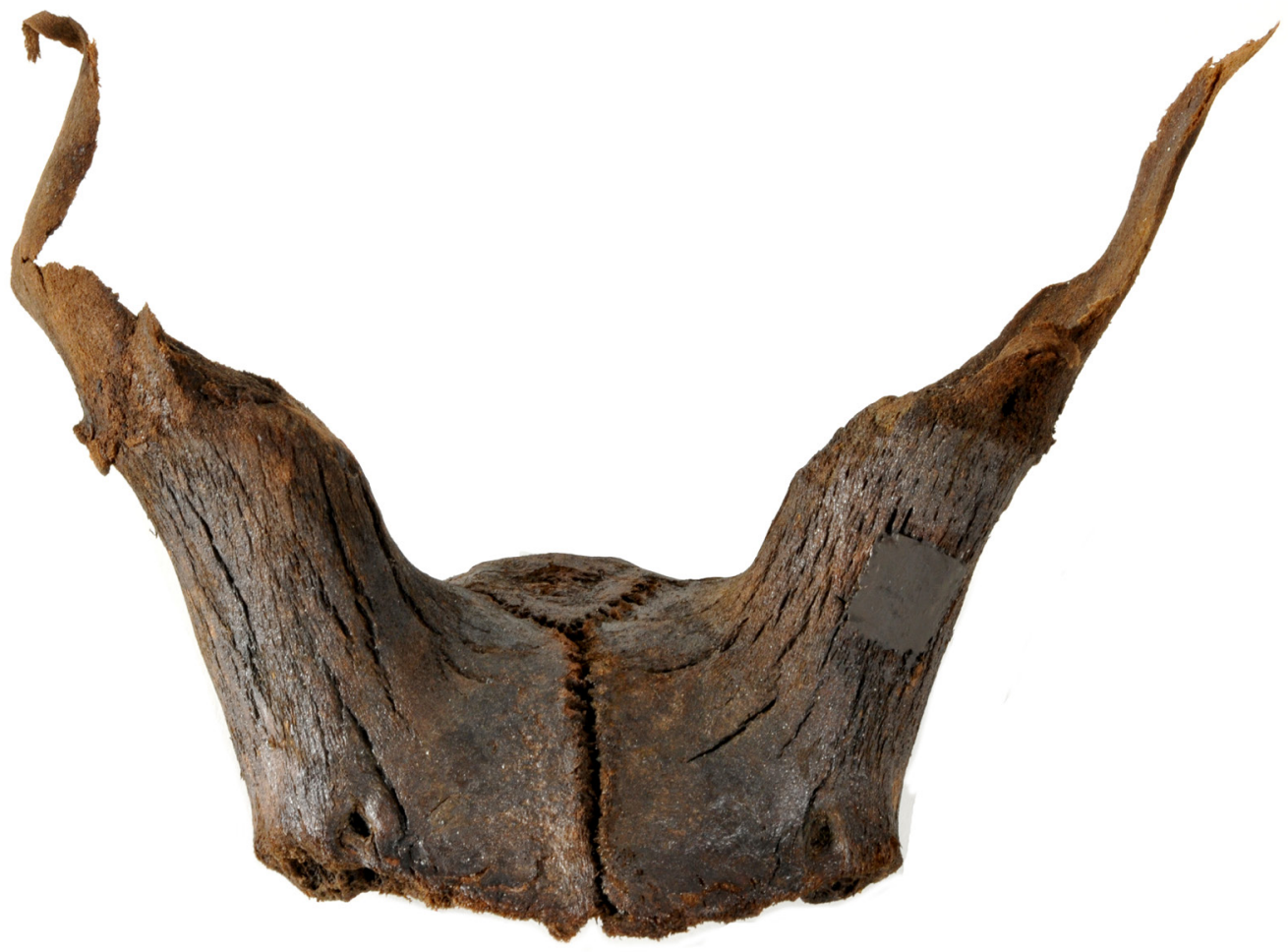

Figure 26.4: Frontlet <99528> (Photograph taken by Paul Shields. Copyright University of York, CC BY-NC 4.0).

$<\mathbf{1 1 3 7 3 2}>$ (Figure 26.3): Left half of a red deer cranium which includes only a small amount of frontal bone, a pedicle and one trimmed antler. The beam is broken short of the trez tine junction and the bez and brow tine removed. 50\% of the compactor circumference remains on the external aspect (Type A), with the spongy tissue removed. Although the details of the worked edges have not survived, the parallel nature of the cut edges suggests that the groove-and-splinter technique was used to remove the compactor. The methods used to remove the spongy tissue are unknown, but it has been applied extensively to the basal portion of the antler. The section of skull that remains appears to have been humanly modified. The pedicle and burr of the antler have also been modified so that there is a smoothed, possibly ground down, area on the medial aspect, possibly linked to the removal of the spongy tissue from the antler. The bone and antler are demineralised and also slightly compressed. Some of the surface detail on the antler has been lost due to a combination of the depositional and demineralisation processes.

$<99528>$ (Figure 26.4): Partial cranium of a red deer that has been modified so that only a small amount of left and right frontal bones, complete pedicles and a small amount of antler remain. The modification of the skull has resulted in scalar flaking around the rim which has similarities with $\langle 103625\rangle$, in that the rim surface has an abraded appearance, and was probably ground with a coarse stone pebble, as our experiments have revealed comparable traces (Little et al. 2016). Although the levels of preservation recorded on <99528> appear to deteriorate towards the distal extents of the piece, several observations can be made as to the ways in which the antlers have been worked. The burrs have been removed on the anterior-external aspect, but remain intact on the internal aspect. The misshapen but intact lower beams demonstrate reduction in that they are missing c. $50 \%$ of their circumference, and the scooped shape of the basal junction implies that similar scraping has been carried out on both the left- and right-sided antlers as has been noted on other frontlets. The retention of the external aspect of the beam classifies this as a Type A frontlet. The pedicles appear to have been modified with a chopping action, probably with the use of a flint axe, to create a downward-sloping angle on their medial aspect. Both the bone and antler are demineralised and have a rubbery consistency. Due to the demineralisation process the bone has bloated and warped creating cracks and splits in the cortical bone. It is possible to see the white mineral gypsum within these splits. 

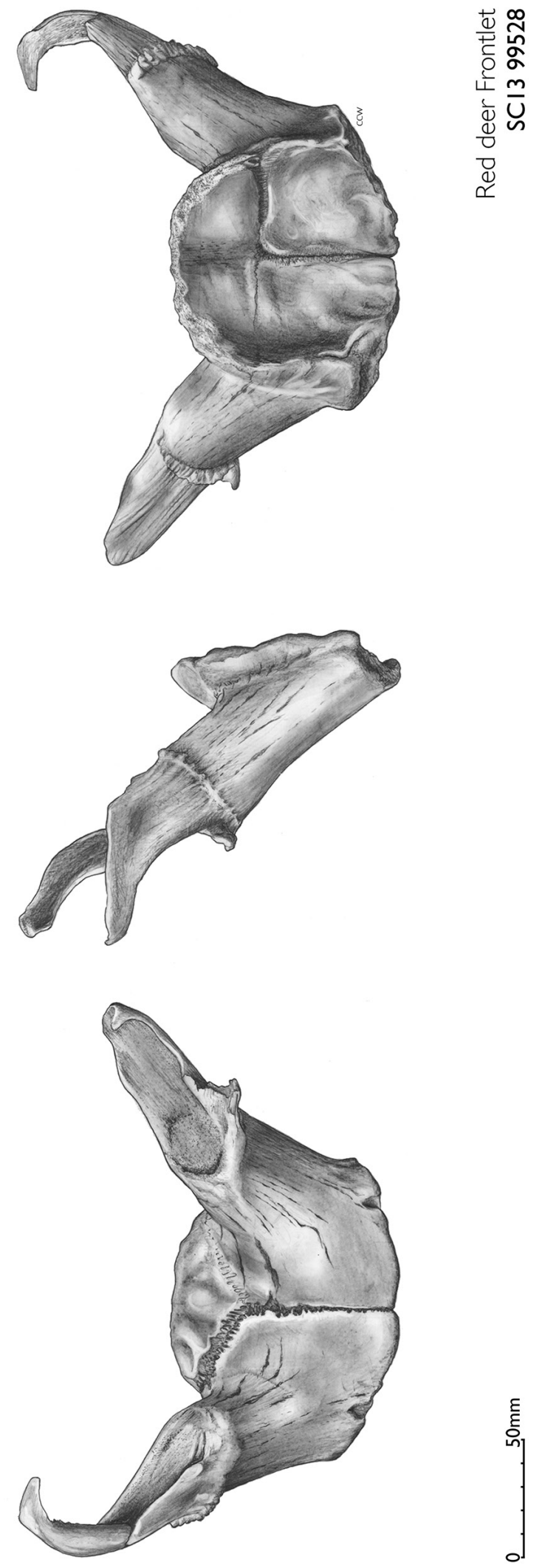
$<\mathbf{1 0 3 6 2 5}>$ (Figures 26.6 and 26.7): Partial cranium of a red deer which includes partial frontal and parietal bones, with pedicles and associated antler beams and tines. Both the skull and antler have been humanly modified, trimmed and worked. The antler has been trimmed and also split in half by groove-and-splinter working. Portions of beam and brow tine of both the left- and right-sided antlers remained intact whilst the artefact was in situ, although these became fragmented during excavation. Evidence for the application of the groove-and-splinter technique is evident across both the beams and brow tines, with continuously smooth and longitudinal facets consistent with grooving. This has retained the postero-external portion of the beam, and the lower $50 \%$ of the brow tine's circumference. Although no working marks within the beams could be positively identified, the manner in which the spongy tissue has been so completely removed from the internal structure of the antler suggests strongly that scraping was employed, after grooving had removed the compactor tissue. Again, although no working marks survive, the smooth profile of the base of both the left and right antler suggest that scraping has been applied to create this hollowed out shape. The lack of visible scraping marks is curious, as substantial quantities of work would have been required to create this effect. The lack of scraping marks may be indicative of wear or abrasion in use, post-dating the manufacture of the artefact. However, this region does coincide with an area of highly localised poor preservation, and so the loss of surface detail is more likely to be associated with this phenomenon.

Two perforations have been created on the parietal bone, each in the region directly posterior to the orbital arches. These are surrounded on both the internal and external aspects by a large number of deeply etched gouge marks, radiating centrally from the perforation itself and extending onto the lower aspect of the adjacent pedicle. These are consistent with the perforation through the nicking technique being applied from both the internal and external aspects of the cranium. As such, they must have been carried out following the removal of the brain, in order to allow access to the internal aspect of the parietal bone. The right perforation also features a smoothed surface on its interior, extending around approximately $30 \%$ of the total circumference of the perforation itself. This smooth area has a light polish adhering to it and it appears to directly overlie the surrounding nicking marks, thus post-dating their creation.

This smooth surface appears unlikely to have been created during the manufacture of the frontlet. Although both drilling and boring are capable of producing similar polished surfaces, the uneven and jagged edge of the remaining $70 \%$ of the perforation circumference attests to the fact that the perforation had been completed prior to the creation of this smoothed surface. As such, it would seem strange that either technique would be applied after the perforation had been successfully created through nicking. This strongly suggests that this particular smoothed facet has been created during the use of the artefact, and may relate to materials being passed through the perforation itself.

The bone and antler is robust and shows no sign of demineralisation. However there are small patches of hard grey concretions and also iron staining on the cortical bone of the skull.

Figure 26.5 (page 303): Frontlet <99528> (Copyright Chloe Watson, CC BY-NC 4.0).

Figure 26.6 (page 305): Frontlet <103625>, dorsal and ventral aspects (Copyright Chloe Watson, CC BY-NC 4.0). 


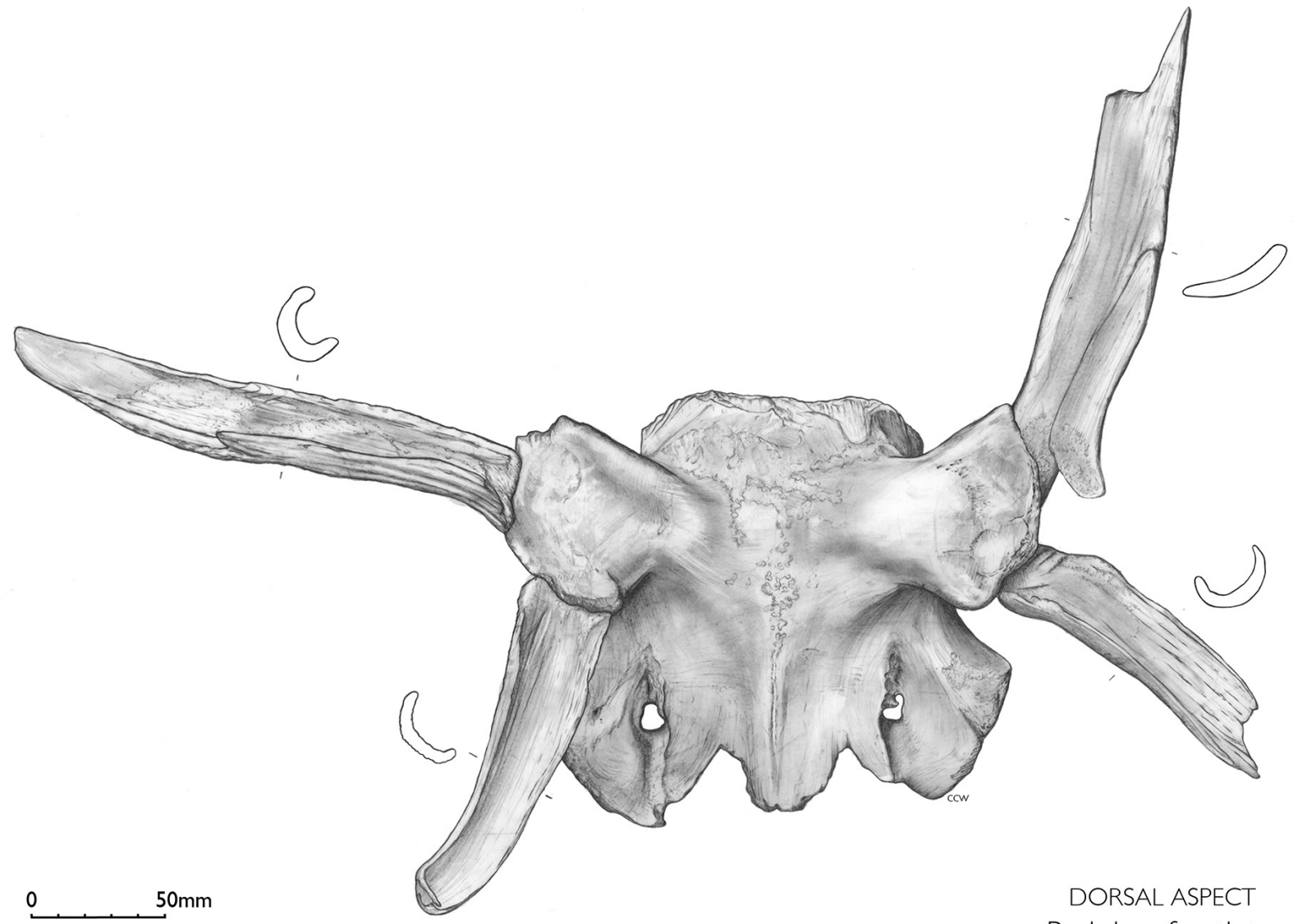

Red deer frontlet SCI3 103625

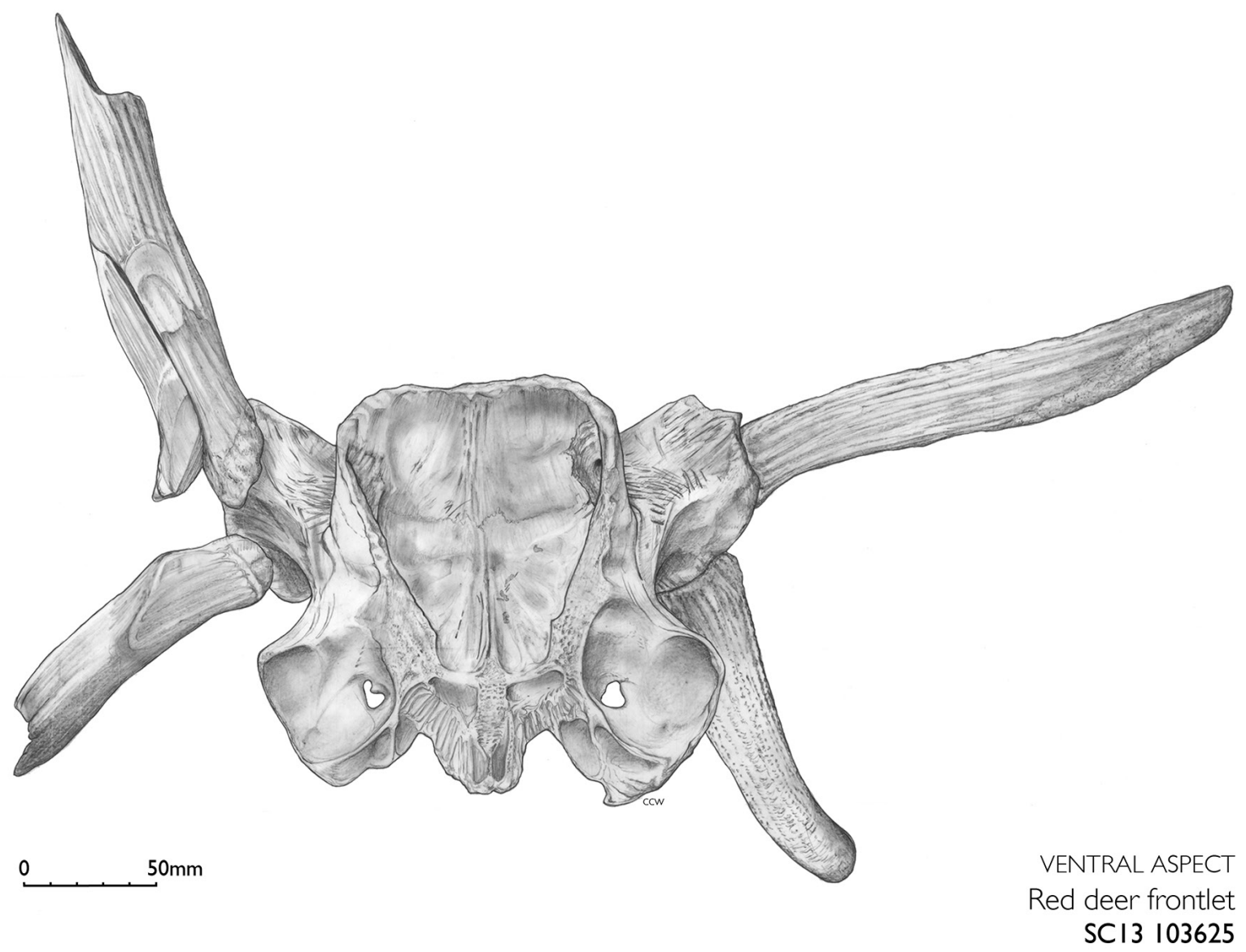




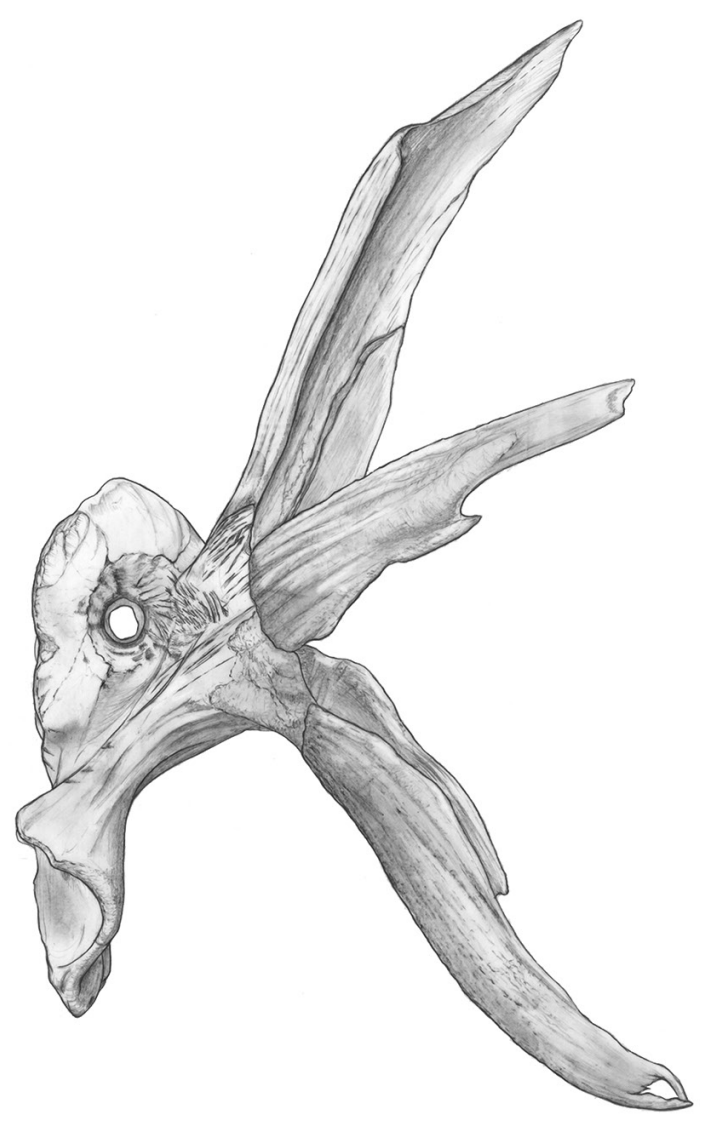

0

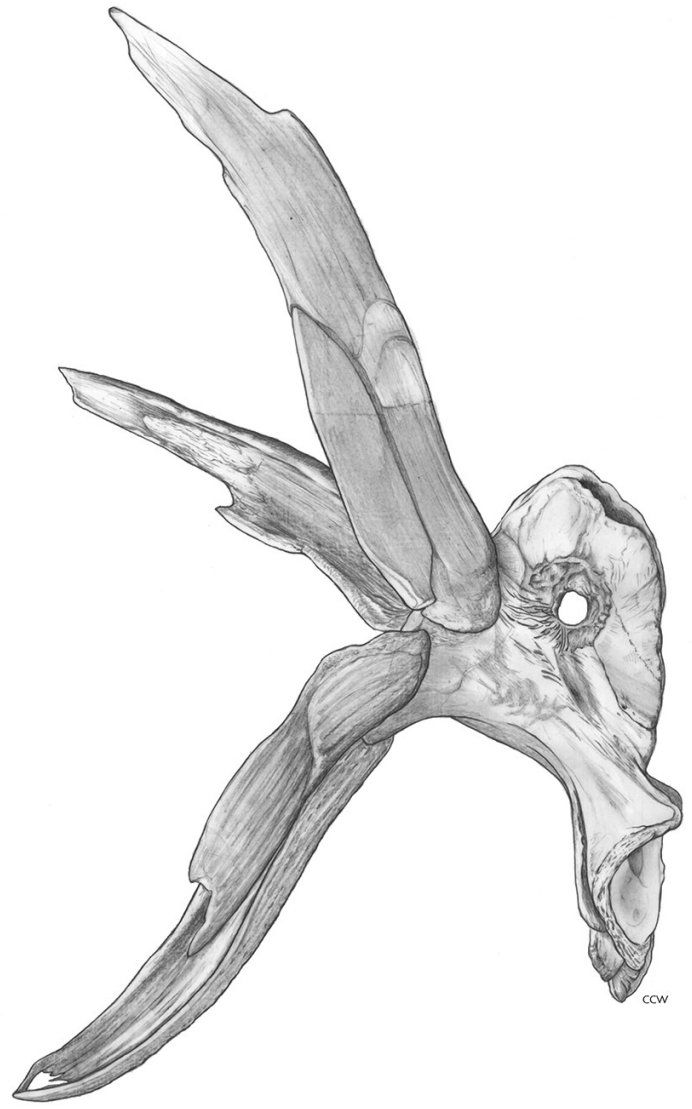

LEFT AND RIGHT SIDE ASPECTS Red deer frontlet $\mathrm{SCl} 3103625$

Figure 26.7: Frontlet <103625>, left- and right-side aspects (Copyright Chloe Watson, CC BY-NC 4.0). 
$<\mathbf{1 1 3 9 0 1 >}$ (Figures 26.8 and 26.9): Partial cranium of a red deer that includes sections of both the left and right sides of the frontal bone, possibly a small section of parietal, pedicles and trimmed antlers. The preservation of this specimen is particularly poor as both the bone and antler are very desiccated and very compressed. The texture of both is comparable to leather. Due to the preservation issues it is difficult to comment on the modification of the skull but the antler appears to have been trimmed and the groove-and-splinter technique applied, retaining the external aspect of the beam (Type A).

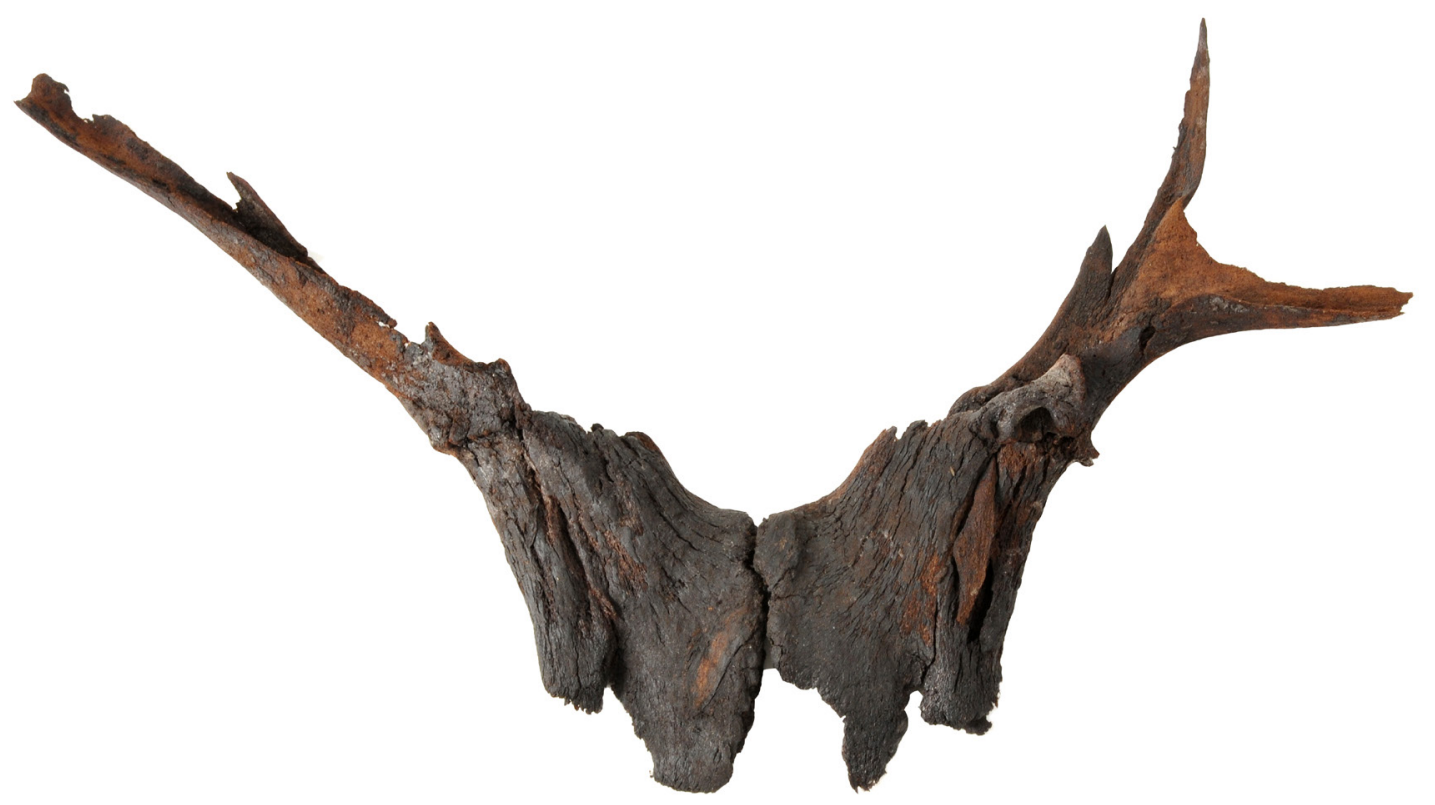

Figure 26.8: Frontlet <113901> (Photograph taken by Paul Shields. Copyright University of York, CC BY-NC 4.0). 


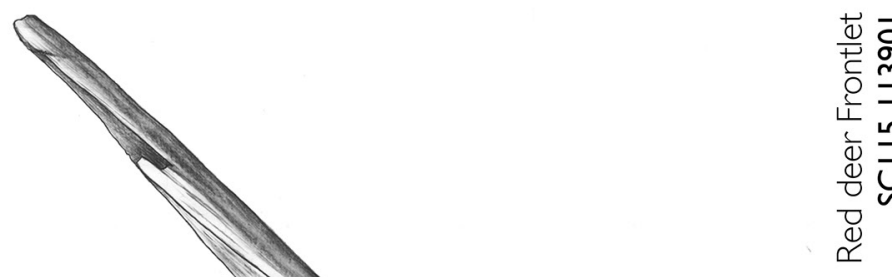

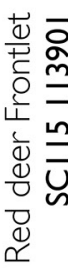
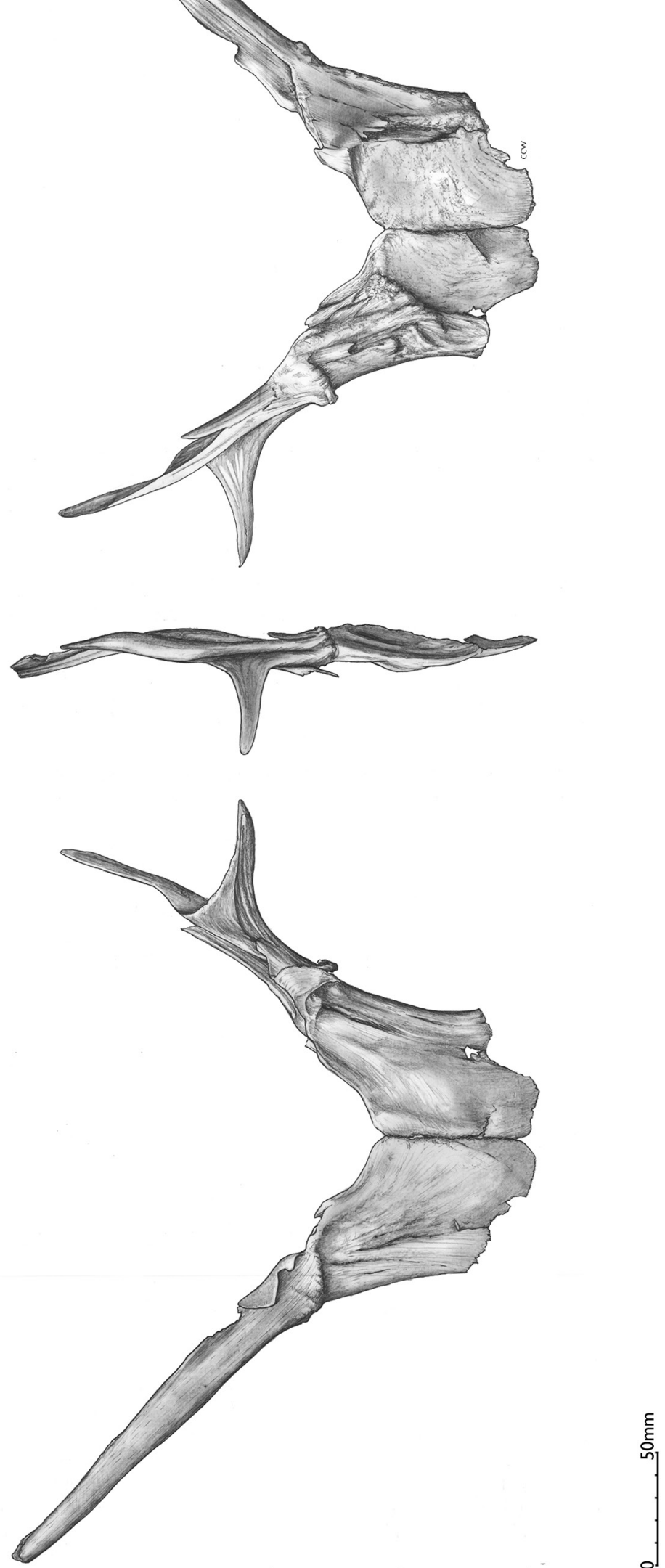


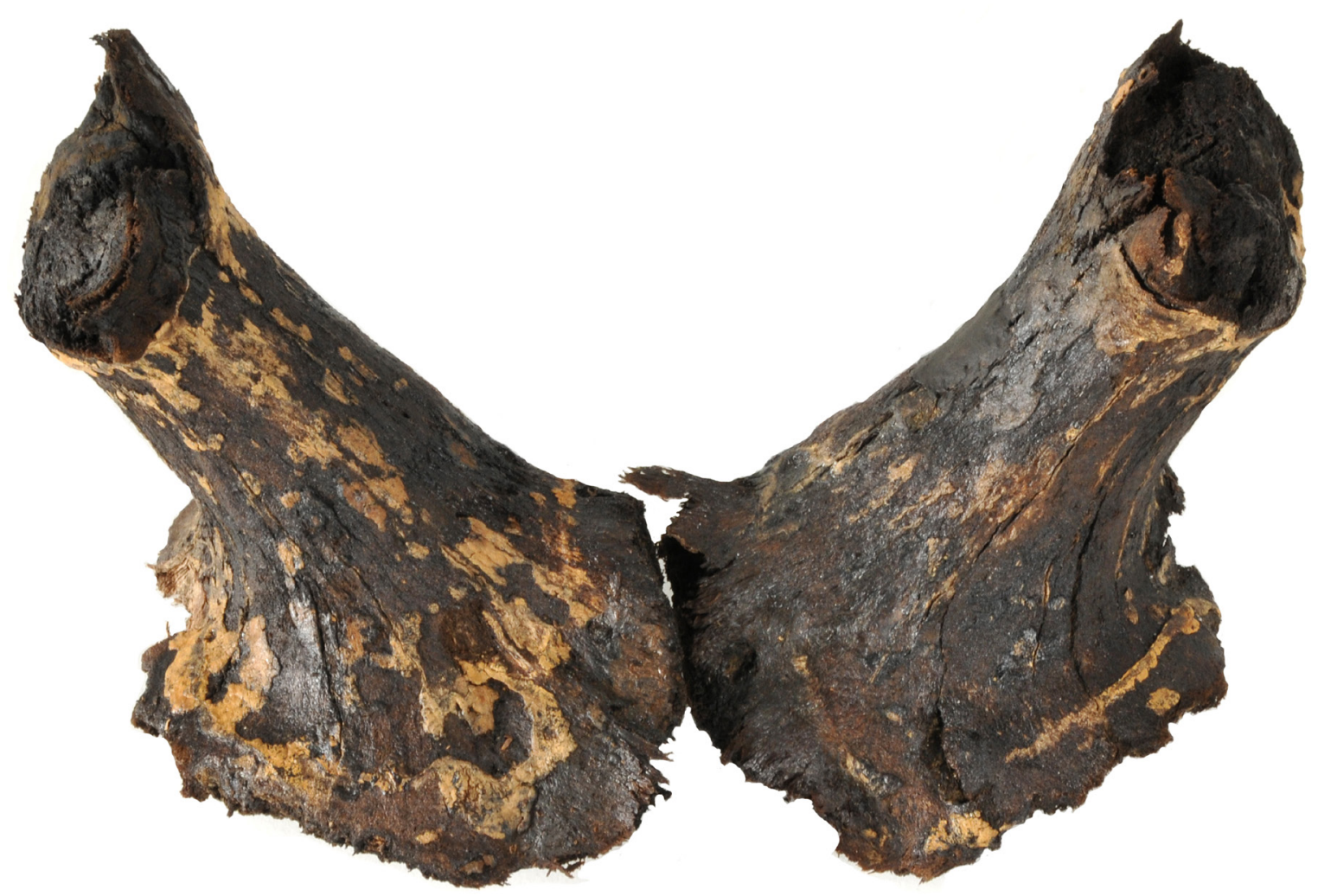

Figure 26.10: Frontlet <114937> (Photograph taken by Paul Shields. Copyright University of York, CC BY-NC 4.0).

$<114937>$ (Figure 26.10 and 26.11): Partial cranium of a red deer which includes sections of frontal and parietal bones, complete pedicles, partial burrs and a small amount of attached antler on the right-side pedicle. This is too fragmentary to allow an assessment of the working techniques used in its reduction, but the small amount remaining intact is situated on the external aspect, classifying this as a Type A frontlet. The base of each burr has been hollowed out with all of the spongy tissue removed. The bone and antler is demineralised and has a rubbery consistency. Due to the demineralisation process the cortical bone of the skull has wrinkled, and splits and cracks have also occurred. Patches of hard grey concretions and fossilized roots were attached to the bone and antler surfaces. The cranium has separated along the suture line on lifting as it was only partially fused. The modification to the cranium has occurred just before the orbits on the frontal bone and just after the frontal parietal suture on the posterior aspect. Both of the pedicles and burrs have been ground and smoothed on a downward angle on the medial aspect.

Figure 26.9 (page 308): Frontlet <113901> (Copyright Chloe Watson, CC BY-NC 4.0). 

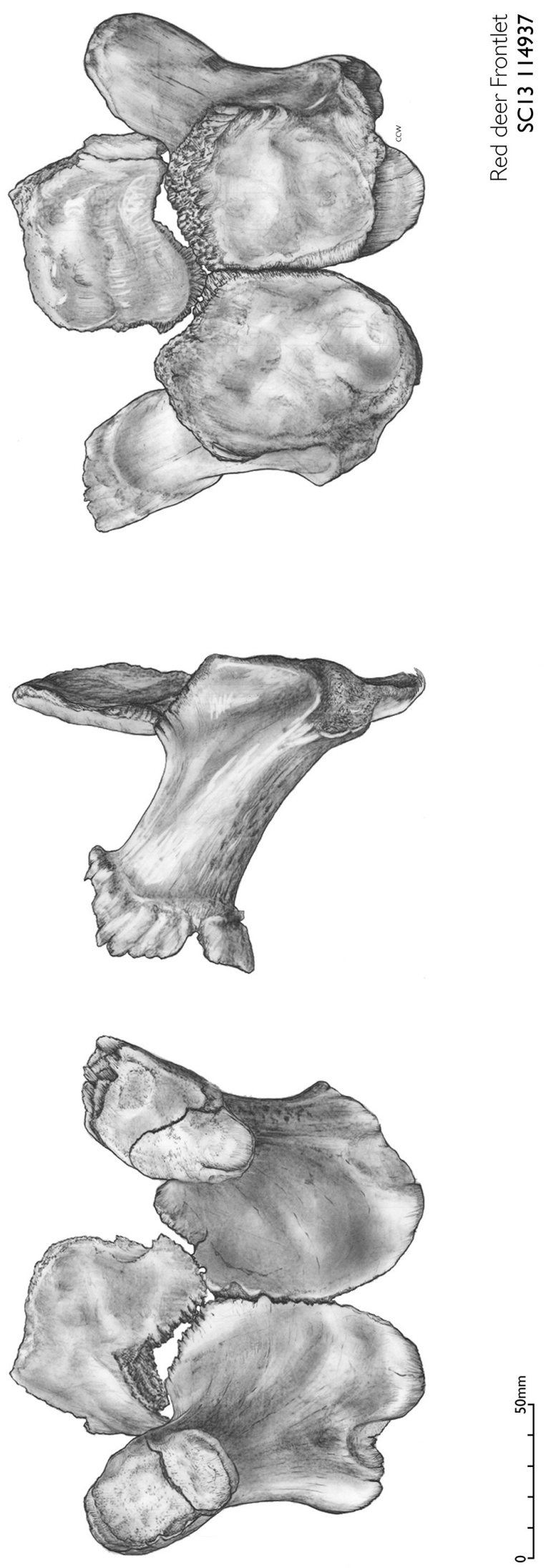


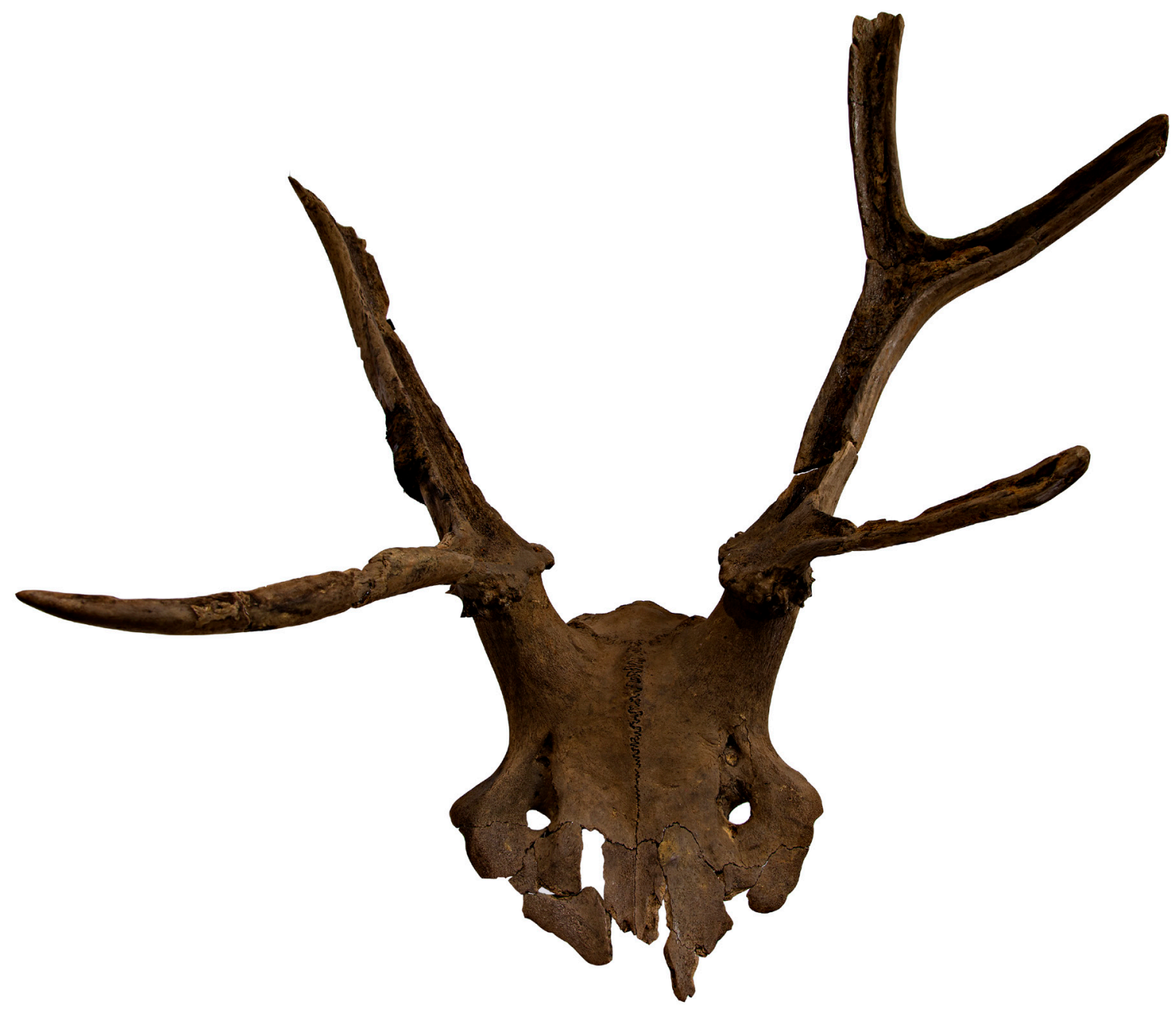

Figure 26.12: Frontlet <115876> (Copyright Neil Gevaux, CC BY-NC 4.0).

Figure 26.11 (page 310): Frontlet <114937> (Copyright Chloe Watson, CC BY-NC 4.0). 
$<$ 115876> (Figure 26.12. 26.13 and 26.14): Modified cranium of a red deer represented by partial frontal bones, partial parietals, complete pedicles and partial antlers. The left antler is broken short below the trez tine junction but features the bez tine with the tip removed and the brow tine. The right antler is broken short below the bez tine junction and so consists of the basal portion and brow tine. A small piece of birch bark, c. $70 \mathrm{~mm}$ in length, was found adhering to the right antler and is included in the illustrations. However, under micro-excavation this was found to be underlain by $5-10 \mathrm{~mm}$ of sediment, meaning that it must have become entangled with the artefact post-deposition and afterwards sediment built up around the antlers. Each antler has had $50 \%$ of the compactor circumference removed and the spongy tissue extracted, leaving the posterior-external aspect of the antlers intact, classifying this as a B2 type frontlet under Clark's typology. Although the cut surfaces are not particularly well preserved, their continuous, parallel edges suggest the use of the groove-and-splinter technique in reducing the antlers. $80 \%$ of the right and left burr circumference is intact, with smoothing used to remove the interior $20 \%$ of each. The techniques used to achieve this smoothing are not apparent. The bone and antler are robust with no sign of demineralisation. More of the frontal bone is represented than is usually seen as the breakage is almost at the suture line of the nasal bones rather than horizontally across the supraorbital fossa like the majority of the other frontlets. The modification to the parietal is horizontally across the posterior aspect just behind the pedicles. The break edges around the circumference of the cranium appear as though they may have been ground or smoothed. There are also possible ephemeral cut marks on the frontal bone near to the central suture, but there is also a small amount of root etching to the cortical bone surfaces of the cranium. 


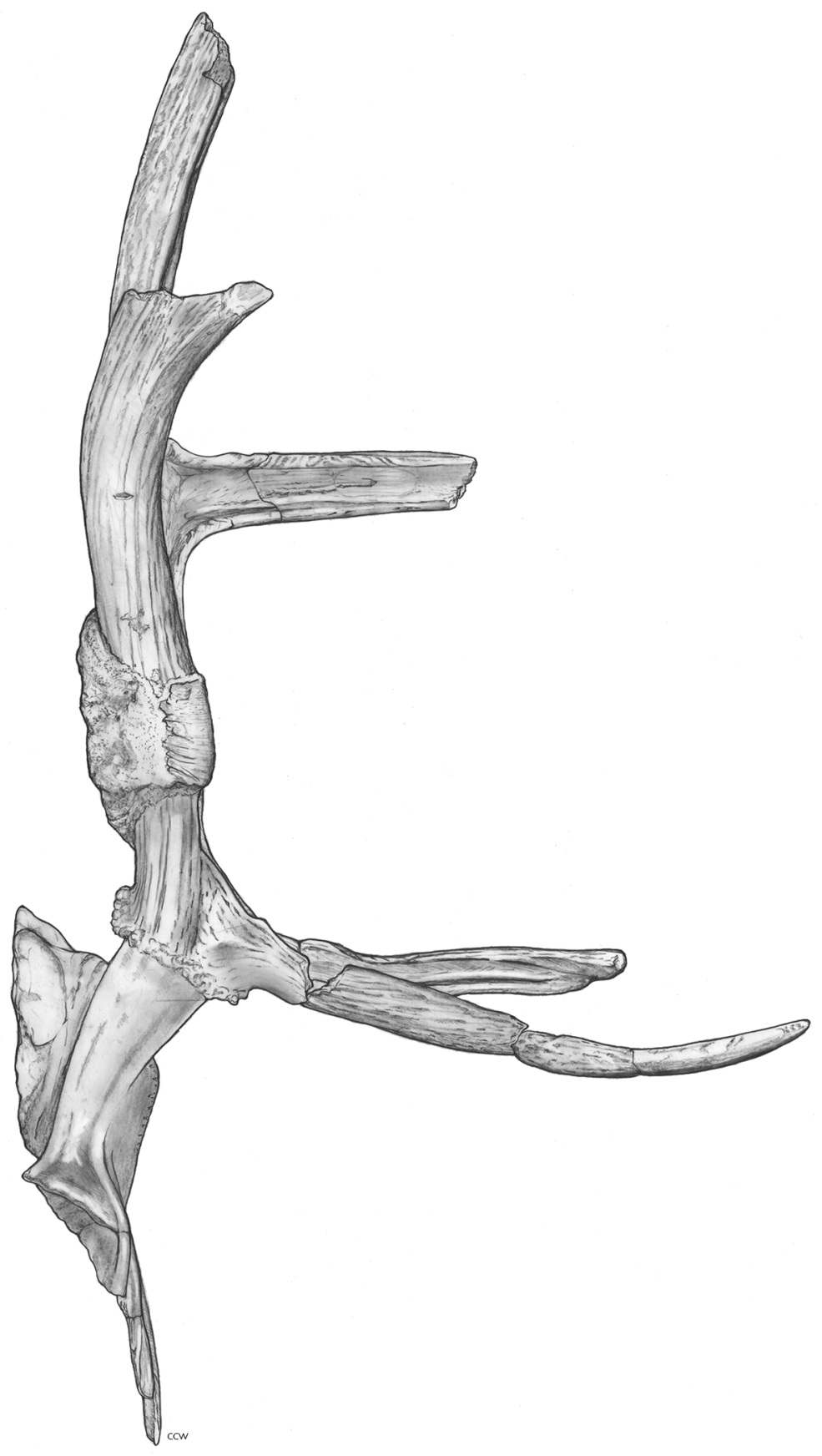

SIDE ASPECT

Red deer frontlet

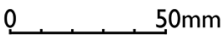

SCI 5 II5876

Figure 26.13: Frontlet <115876> side aspect (Copyright Chloe Watson, CC BY-NC 4.0). 


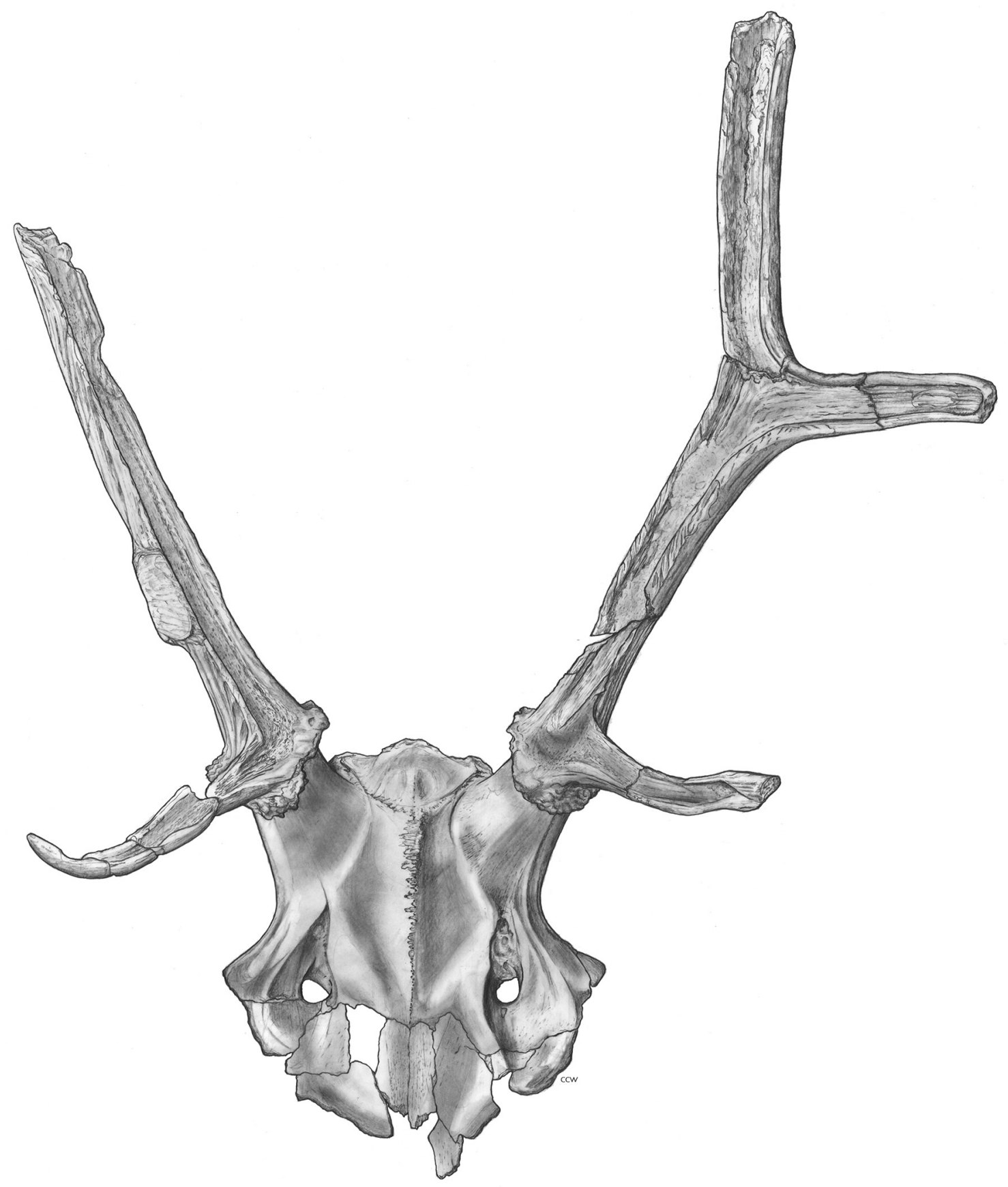

DORSAL ASPECT

Red deer frontlet SCI5 II5876

Figure 26.14: Frontlet $<115876>$ dorsal aspect (Copyright Chloe Watson, CC BY-NC 4.0). 


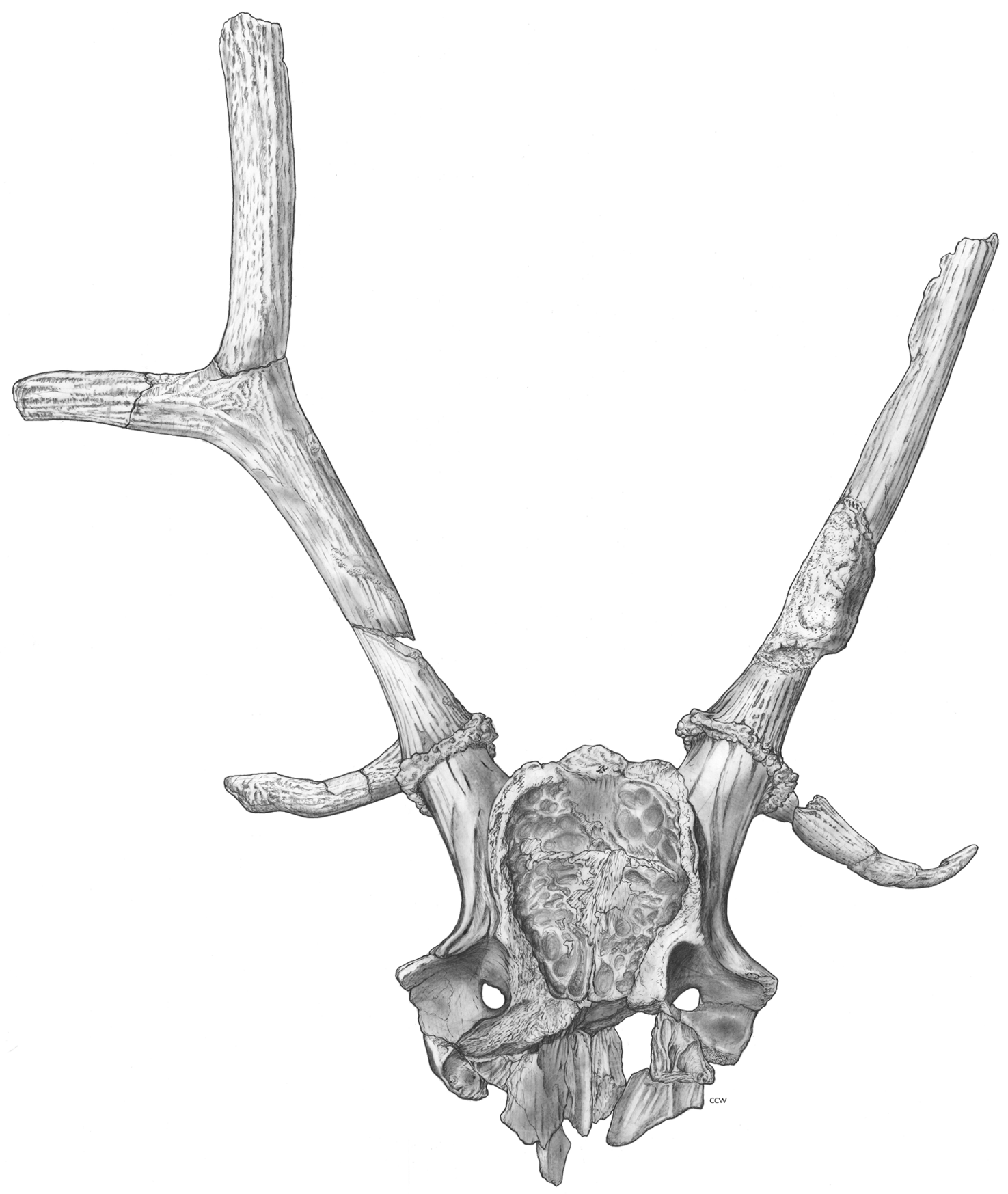

VENTRAL ASPECT

Red deer frontlet $50 \mathrm{~mm}$ SCI5 II5876

Figure 26.15: Frontlet <115876> ventral aspect (Copyright Chloe Watson, CC BY-NC 4.0). 


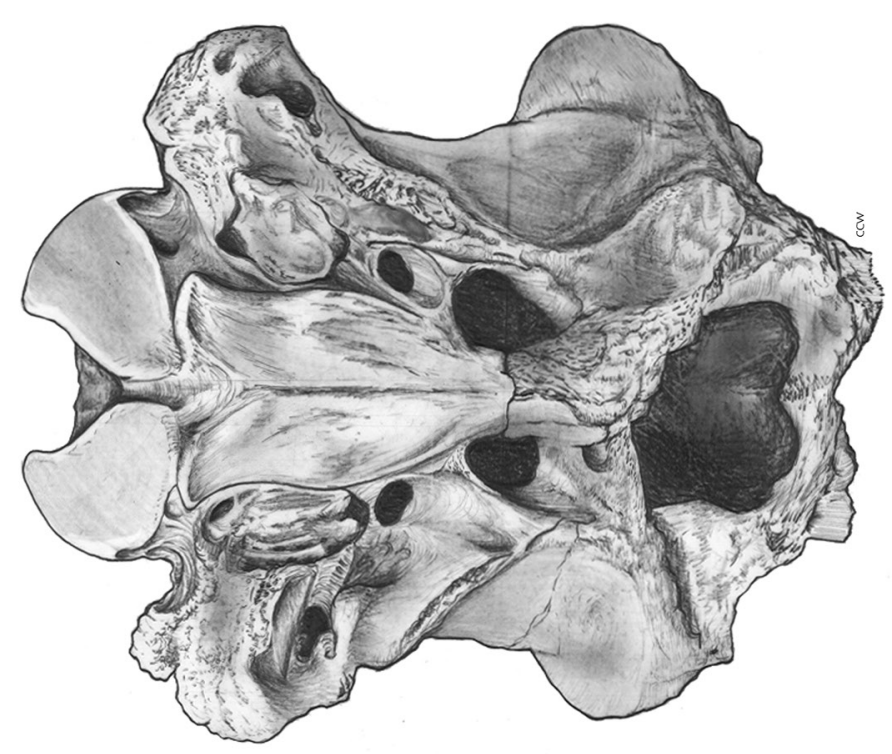

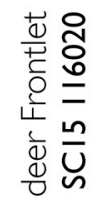

$\ddot{\forall}$
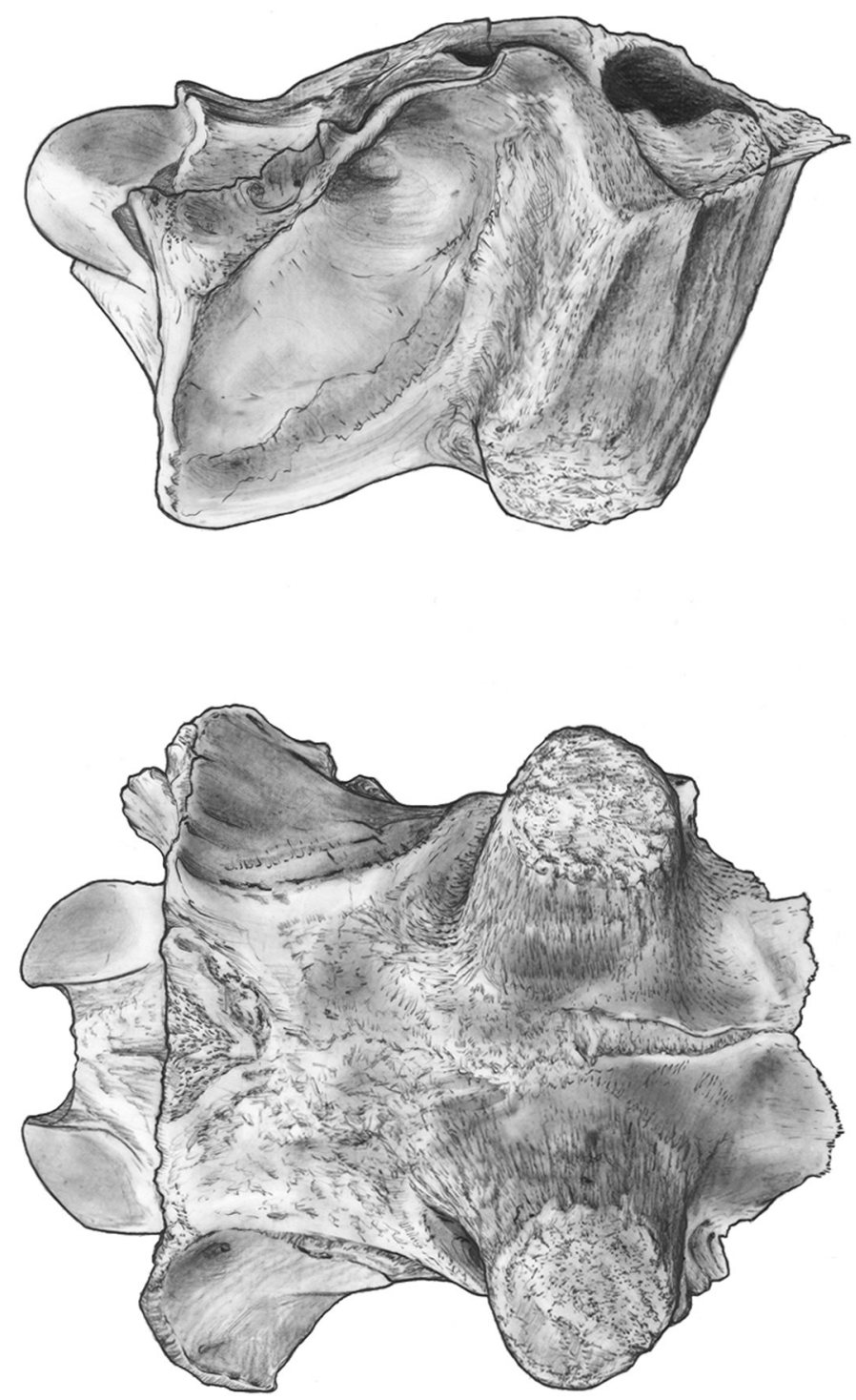
$<\mathbf{1 1 6 0 2 0}>$ (Figures 26.16, and 23.39 and 23.40 in Chapter 23): A partially modified red deer cranium with breakage horizontally across the frontal, above the orbits, which is common in the majority of the other frontlets, but the majority of the brain case is still complete. There are also no antlers attached as they have been naturally shed. The bone is robust on this specimen and there is no sign of demineralisation. However, the surface of the cranium is uneven and there are very defined muscular grooves within the parietals (see Chapter 23). The breakage to the cranium is uneven and jagged, but it does appear some attempt has been made to grind or smooth the rougher, sharper areas of the sphenoid.

Figure 26.16 (page 316): Frontlet $<116020>$ (Copyright Chloe Watson, CC BY-NC 4.0). 


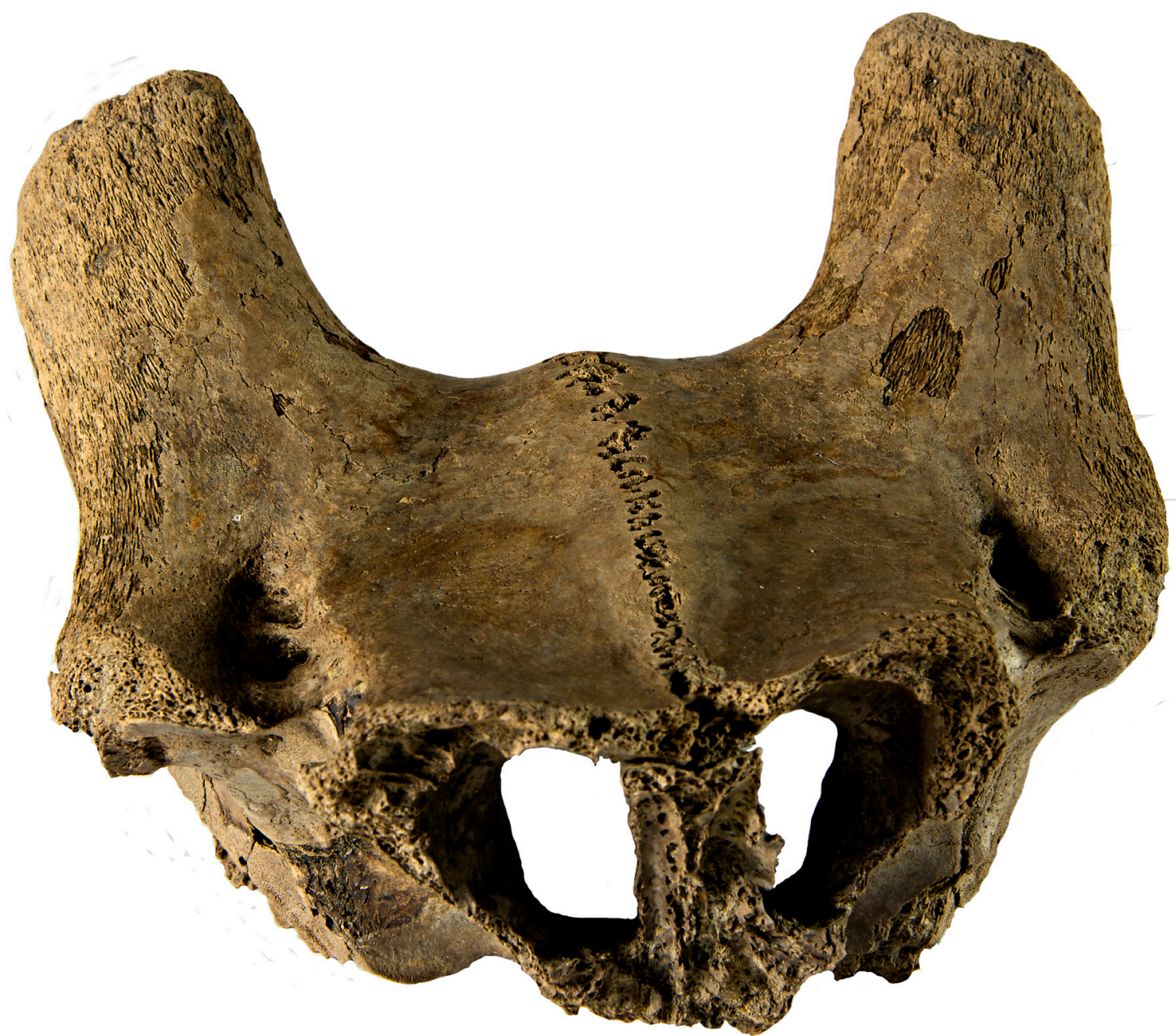

Figure 26.17: Frontlet <116601> (Photograph taken by Paul Shields. Copyright University of York, CC BY-NC 4.0).

$<\mathbf{1 1 6 6 0 1}>$ (Figures 26.17 and 26.18): Partial cranium of a red deer. The pieces of the cranium that remain are the frontal, the parietal and the pedicles. The skull has been broken at the suture of the frontal and nasal, and at the suture of the parietal and occipital. There is evidence of pecking on the internal edge of the parietal, and some fragments of the parietal have become detached from the main body of the cranium during lifting, mostly along the suture line. The frontal suture is very visible and does not appear to have fused significantly. There is a small amount of flaking of the cortical bone on the left side of cranium on the anterior of the pedicle. There is a possible cut mark on the centre of the parietal and also on one of the detached parietal fragments. Also another ephemeral cut mark is present on the partial left orbit. The pedicles are smooth and rounded, though it is difficult to say whether it is from human modification or from post-depositional processes.

Figure 26.18 (page 319): Frontlet <116601> (Copyright Chloe Watson, CC BY-NC 4.0). 

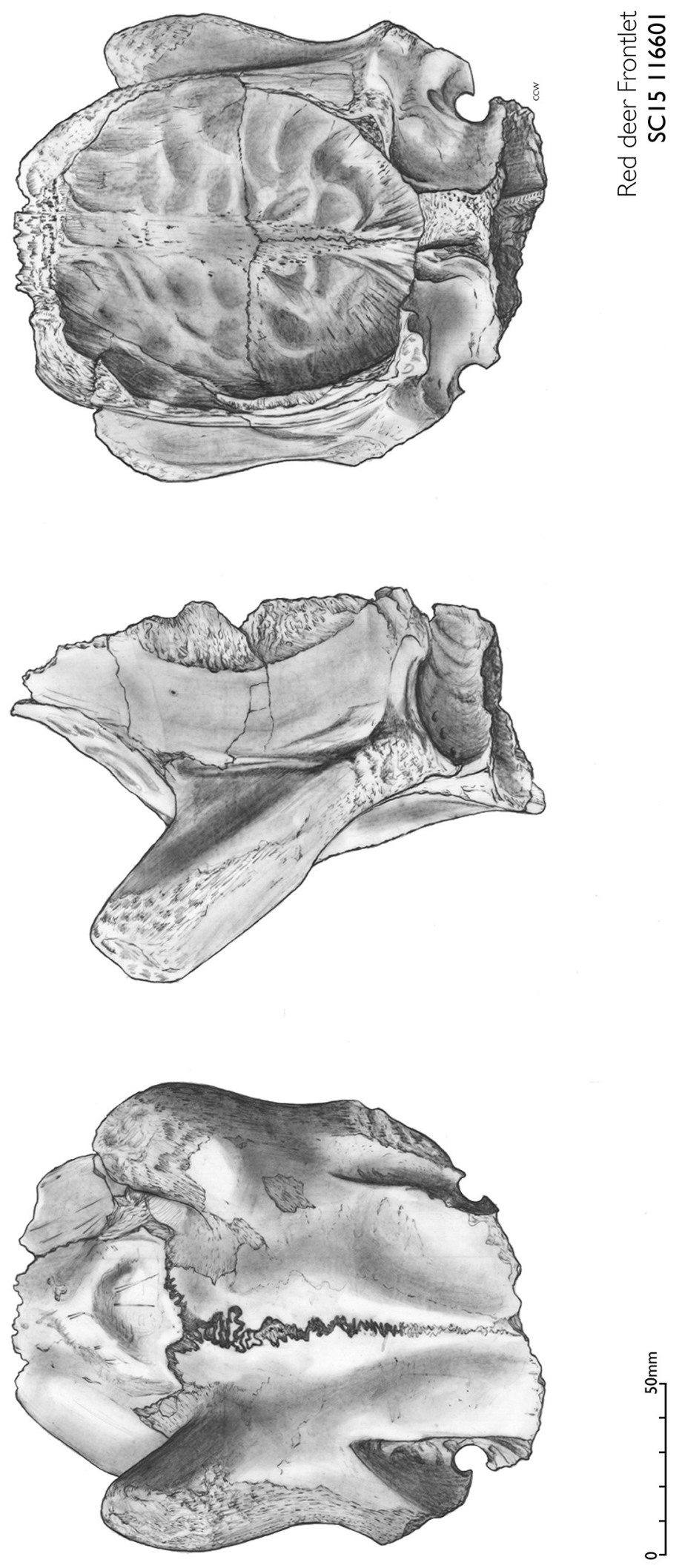


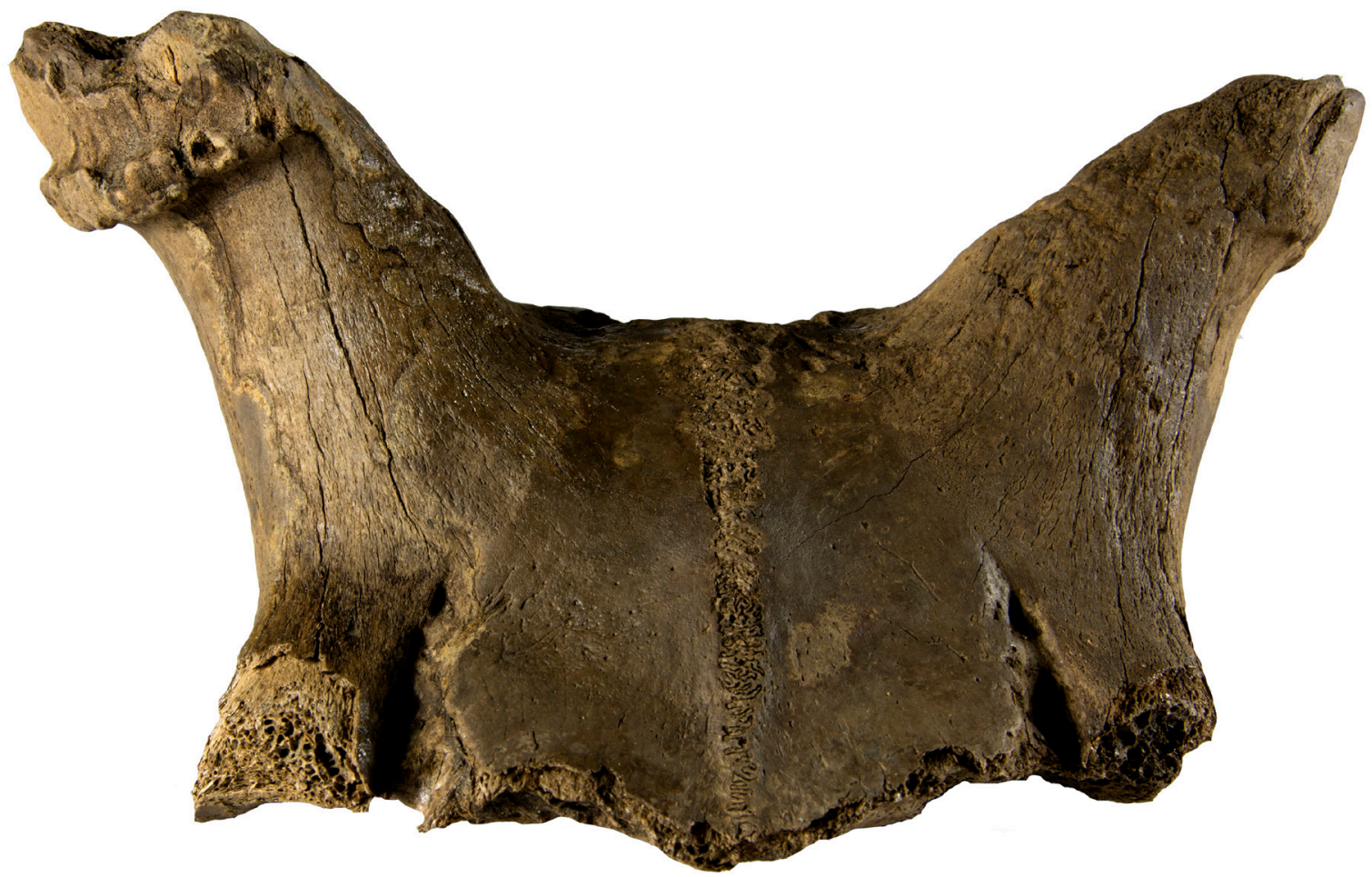

Figure 26.19: Frontlet <116862> (Photograph taken by Paul Shields. Copyright University of York, CC BY-NC 4.0).

$<\mathbf{1 1 6 8 6 2}>$ (Figures 26.19 and 26.20): Partial cranium of a red deer represented by partial frontal and parietal bones, pedicles and a small amount of attached antler. The breakage to the frontal bone is horizontally across the nutrient foramen and there appears to be some purposeful flaking around the break edge. There are a few possible ephemeral score marks on the centre of the parietal bone and also on the left side of the frontal bone close to the sagittal suture. The left-sided burr's circumference is $95 \%$ intact, whilst the right-sided burr has $50 \%$ of the original circumference intact, with the interior aspect having been removed. Both the bone and antler are robust with no sign of demineralisation. However, there was quite a bit of root adhering to the cortical bone surface and also some patches of iron staining.

Figure 26.20 (page 321): Frontlet $<116862>$ (Copyright Chloe Watson, CC BY-NC 4.0). 

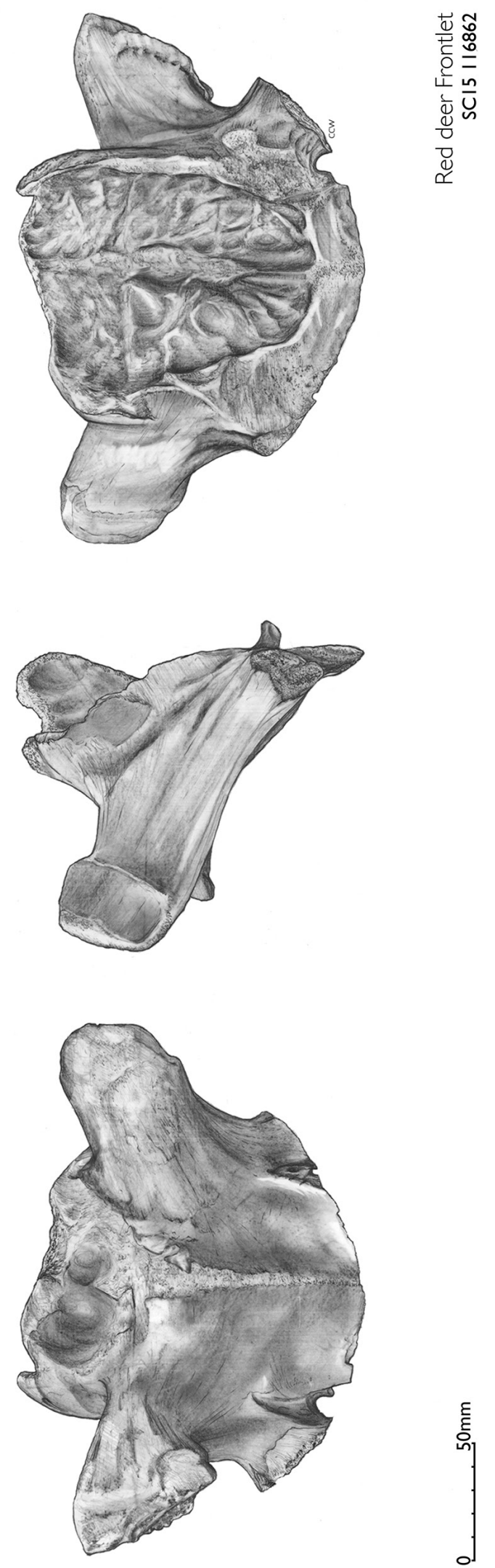


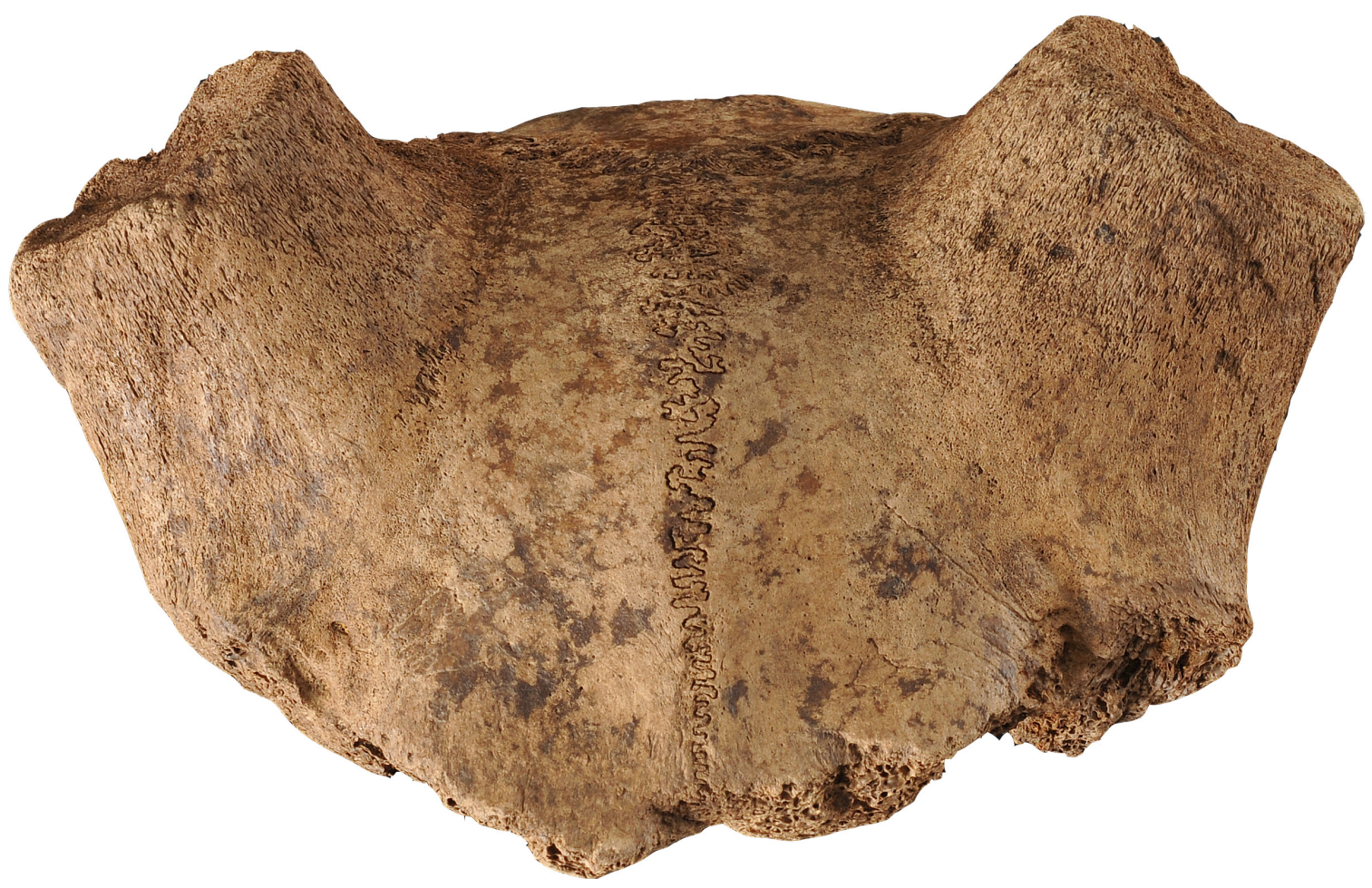

Figure 26.21: Frontlet <116888> (Photograph taken by Paul Shields. Copyright University of York, CC BY-NC 4.0).

$<\mathbf{1 1 6 8 8 8}>$ (Figures 26.21 and 26.22): Partial cranium of a red deer with only a partial frontal and parietal bones present. There are no antlers attached to the pedicles as these appear to have been shed naturally. The breakage to the cranium is uneven and jagged and there is a clear percussion point at the base of the break edge on the parietal. The break to the frontal bone is just in front of the pedicle, before the nutrient foramen. The breakage to the parietal is approximately $10 \mathrm{~mm}$ after the pedicles and horizontally across. The sutures on the skull are still clearly visible. The area just underneath the pedicles at the very edge of the parietal (almost at the suture) features impressions and score marks suggestive of carnivore gnawing. There is a possible molar impression on the left side and tooth scores. The evidence is slightly more ephemeral on the right side yet still present. There are some possible ephemeral cut marks on the parietal with directionality anterior to posterior, located towards the right-hand side.

Figure 26.22 (page 323): Frontlet $<116888>$ (Copyright Chloe Watson, CC BY-NC 4.0). 

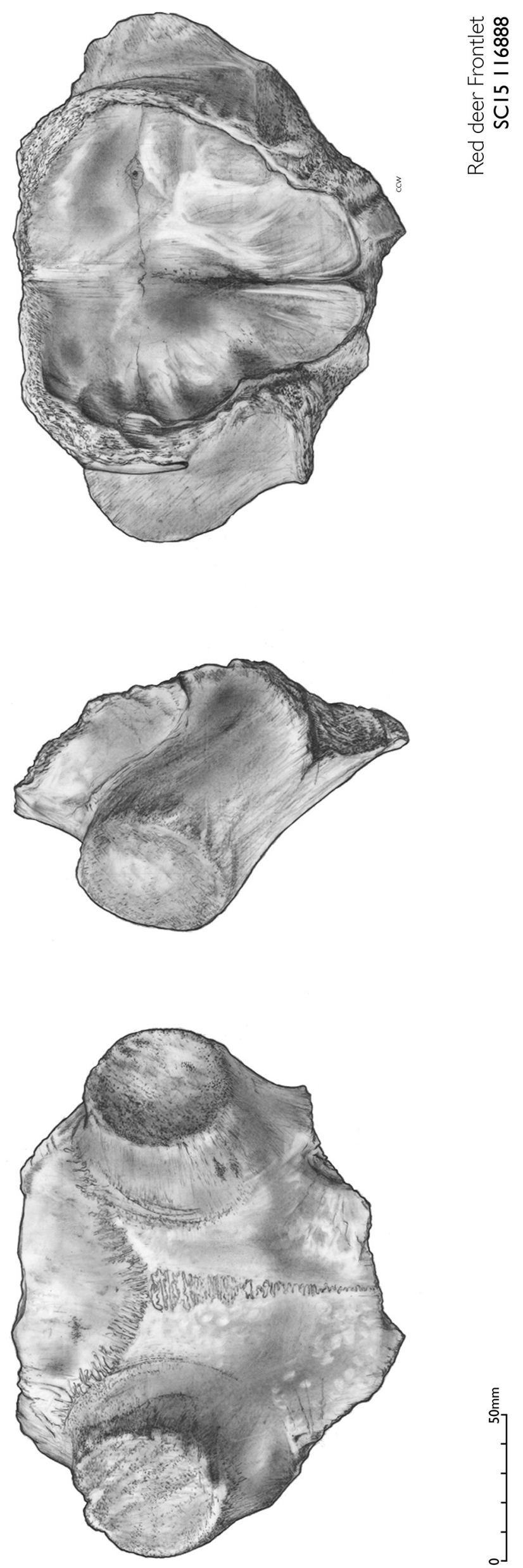


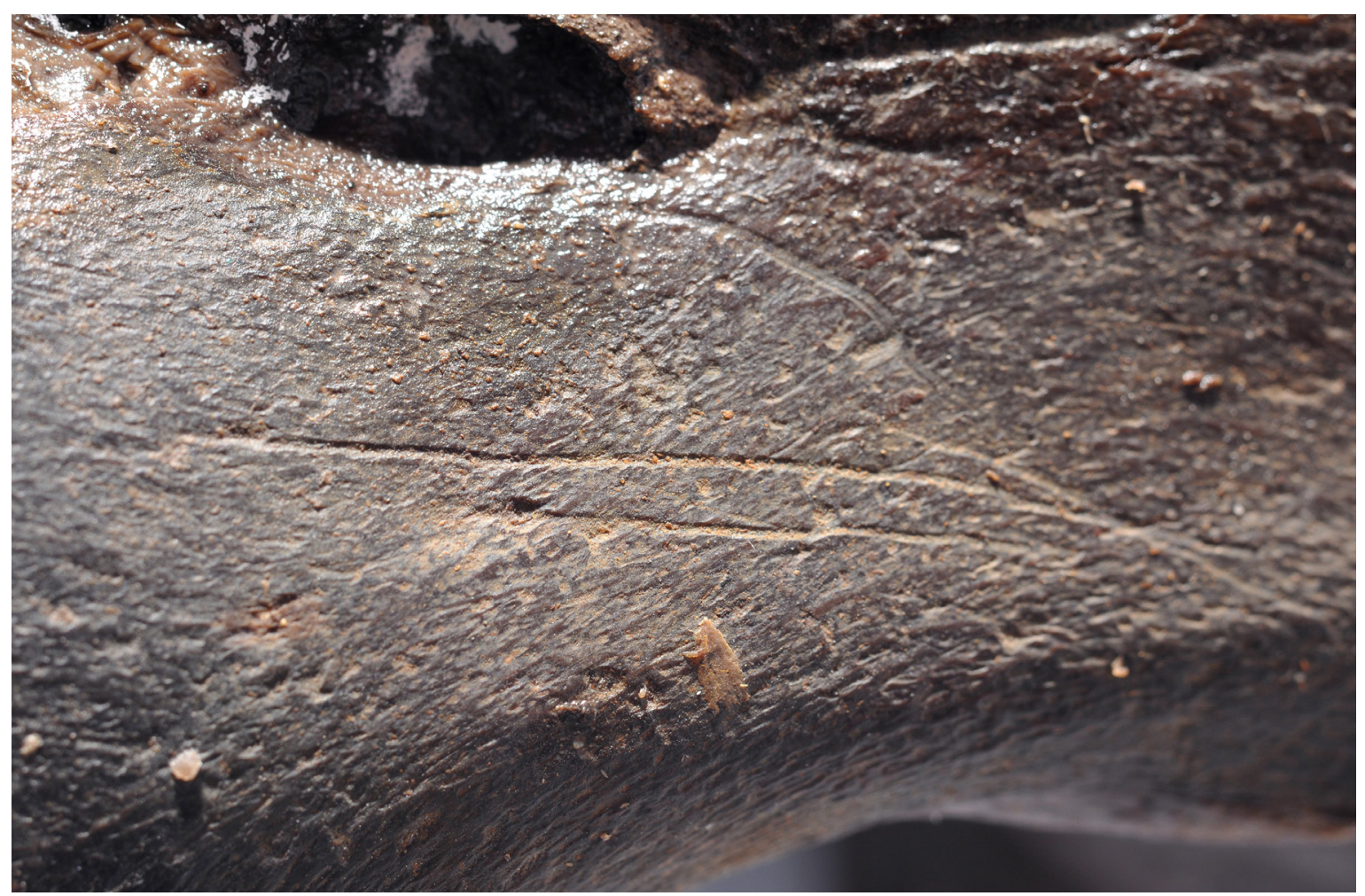

Figure 26.23: Frontlet $<117803>$ exhibiting cut marks (Photograph taken by Paul Shields. Copyright University of York, CC BY-NC 4.0).

$<\mathbf{1 1 7 8 0 3}>$ (Figures 26.23 and 26.24): Partially modified cranium of a female red deer with only a section of frontal bone being retained but the majority of the braincase still intact. The frontal bone has been broken horizontally across, allowing approximately half of the orbits to remain attached. There was also a fragment of zygomatic associated but not attached to the main body of the cranium. It appears as though the sharper edges of the sphenoid have been ground or smoothed down. There are also three possible parallel cut marks to the edge of the left orbit but they are very ephemeral. The majority of the bone is robust but the right side of the cranium is partially demineralised. The cranium is very slightly warped and compressed due to this and is therefore leaning towards the right (softer) side. There is a small amount of excavation damage to the right parietal as a result of the demineralised bone.

Figure 26.24 (page 325): Frontlet <117803> (Copyright Chloe Watson, CC BY-NC 4.0). 

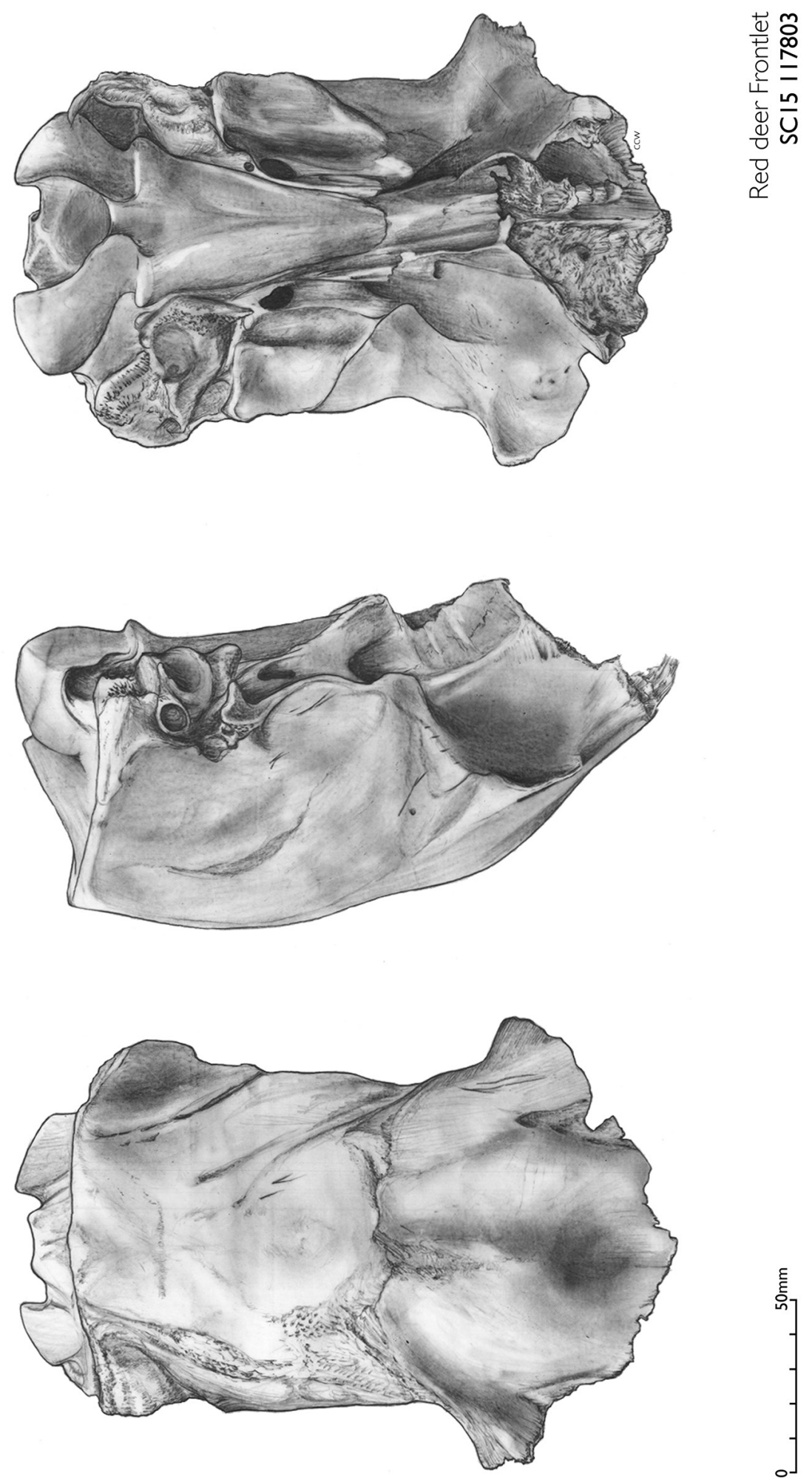


\section{Experiments}

The variation apparent within the 2004-2015 frontlet assemblage prompts a series of new questions concerning their methods of manufacture. Is this diversity representative of a châine opératoire sequence, with individual finds being abandoned at different stages of the production process, or typological variation within the form of the finished artefacts? To investigate these questions, a series of experiments were undertaken. These have helped to demonstrate the techniques used to reduce a fleshed deer head to the trimmed frontal portion seen at Star Carr. This work has also highlighted the extensive labour investment involved in the reduction of the antlers via the groove-and-splinter technique (Little et al. 2016).

In summary, these experiments found that the initial reduction of the skull was achieved by first skinning the head, using a tranchet adze to begin hide removal at the base of the antlers, and then covering the portion of skull which was intended to be retained with damp clay. The head was then placed within the hot embers of a small fire for several hours, after which point the exposed skull was removed through direct, repetitive percussion carried out with a small hammerstone (Figure 26.17). Using subtle variations of this technique, the lower part of the skull could be removed rapidly and then the edges of the braincase defined with a high degree of accuracy. This process left cut marks associated with de-skinning on the outer surfaces of the frontlet, cut marks within the braincase associated with the removal of the brain, and a series of shallow, scalar negatives of bone removal around the rim of the braincase. These experimentally recreated working marks were identified across all of the crania described here as frontlets.

As frontlet manufacture requires the use of clay and a hearth setting we can expect that the reduction of the skull would have been carried out on the dryland and not in the wetland. As such, a distinction needs to be drawn between the places where skulls were worked during frontlet production and the wetland contexts into which they were later deposited.

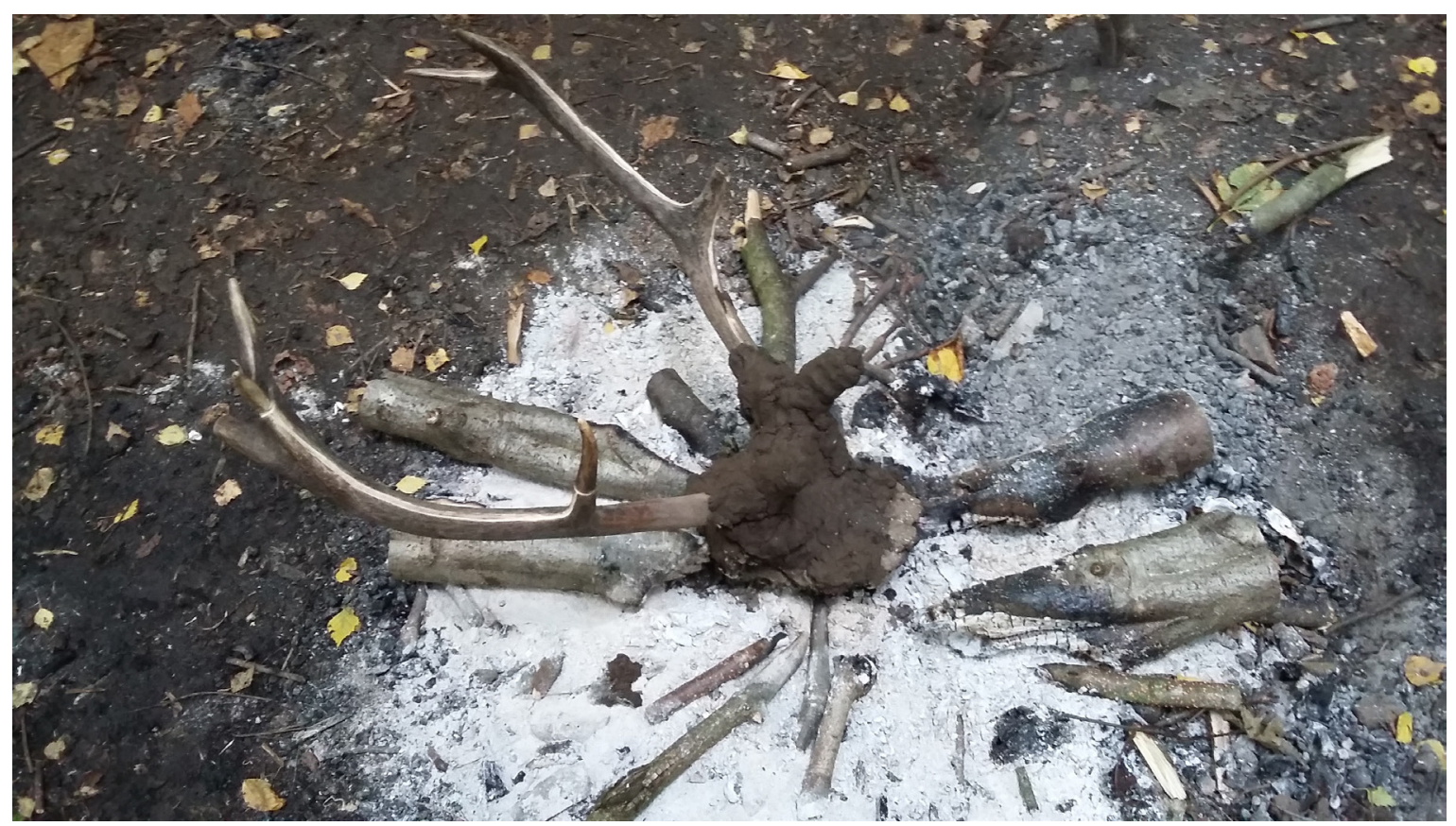

Figure 26.25: Experimental research into the manufacture of antler frontlets through the use of fire (Copyright Star Carr Project, CC BY-NC 4.0).

To watch this video, scan the QR code with your mobile device or visit DOI: https://doi.org/10.22599/book2.1

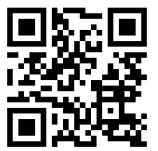




\section{Discussion}

\section{A technological approach}

These insights allow a more refined definition of red deer frontlets to be applied to the new material from Star Carr. A unifying factor within the assemblage is the evidence for the removal of the mandible, maxilla and nasal bones. The latter are notably absent from the wetland faunal assemblage, suggesting that this processing was carried out prior to deposition and are not attributable to taphonomic factors. When compared to the more-intact cranial fragments within the faunal assemblage, the frontlets again stand out. Generally, crania are surprisingly scarce at Star Carr, and the few which do survive include an articulated dog skull with no signs of modification, an elk skull with the maxilla and nasal bones intact, a female roe deer with the partial nasal bones and maxilla intact, and a female red deer skull which, whilst representative of similar elements to $<117803>$, lacks any clear working traces and retains substantial portions of the zygomatic arches. With this in mind, the consistency in the working of the cranial bones apparent in the frontlets is striking and suggests that these red deer crania were treated in a different manner to other examples.

Beyond this cranial reduction, the frontlets are worked to varying extents, with antlers (when present) being reduced through the groove-and-splinter technique to varying degrees, the parietal being trimmed to various extents, the lower braincase removed, and perforations being created. When antlers are present, an apparently key feature of the frontlets is the removal of the spongy tissue from the split beams and tines. This is in marked contrast to the red deer antlerworking debitage pieces within the assemblage, which often feature both shed and unshed beams which have considerable proportions of the beam circumference removed but which retain the spongy tissue. Whilst this cannot be considered a definitive feature of the frontlets (the specimens lacking antlers in the first instance clearly cannot be defined under this criteria), its consistency helps to mark out this type of artefact from barbed point debitage and strongly suggests an attention to the finished form of the artefacts.

This classification has some profound implications for the ways in which the frontlets can be understood. Firstly, it is noted that several of the 2013-2015 specimens do not feature antler. $<116601>$ and $<116888>$ have had their skulls treated in the same way as the other frontlets, but have used the heads of male red deer which have recently shed their antlers. $<117803>$ is the skull of a female red deer, which lack antlers, and has been processed in the same way. The production of these artefacts would have involved the investment of a significantly smaller amount of time and effort, and also demonstrates that the extraction of antler for the production of barbed points was not always a key consideration in the creation of a frontlet. It has important implications for the meaning of the finished artefact, developing material connections between different animal gender identities, and at different times of the year, than has been previously assumed for the Star Carr frontlets (Conneller 2004; Conneller 2011).

Secondly, the extent to which the braincase is reduced is also a key consideration. The effect that this has on the finished form of the artefacts is pronounced, as is their suitability for use as a headdress. It would therefore be tempting to view the frontlets with substantial portions of the braincase still intact as unfinished objects, abandoned part-way through their manufacture. However, as noted above, the site of deposition for these artefacts could not have been that of manufacture, making the suggestion of accidental or casual discard during manufacture a poor fit for the contextual data available. These may well be unfinished artefacts, but their deposition appears just as considered and deliberate as that of the complete specimens.

Thirdly, it can be seen that the creation of perforations on the Star Carr frontlets is far from a definitive factor. Within Clark's assemblage, only eight of the 21 frontlets are listed as featuring perforations, whilst the 2013-2015 data brings the overall total to nine of 33. Recent work has drawn attention to the presence of perforations as a key way to define this particular type of artefact across Europe in the Early Holocene (Street and Wild 2015). However, the data from Star Carr suggests that within the assemblage, a technological approach may be more suited to classifying these artefacts rather than a typological one. It is the similarities in the châine opératoire of the artefacts at Star Carr which mark them out as a distinct group of artefacts, rather than a single typological feature.

Finally, if this technological definition is to be followed, it also worth considering its relevance to other species represented within the Star Carr fauna. In particular, of the six roe deer crania recovered during the current excavations, five show similar patterns of fragmentation with the maxilla, mandibular and nasal bones removed and the frontal and parietal bones retained. (Figure 26.18). 


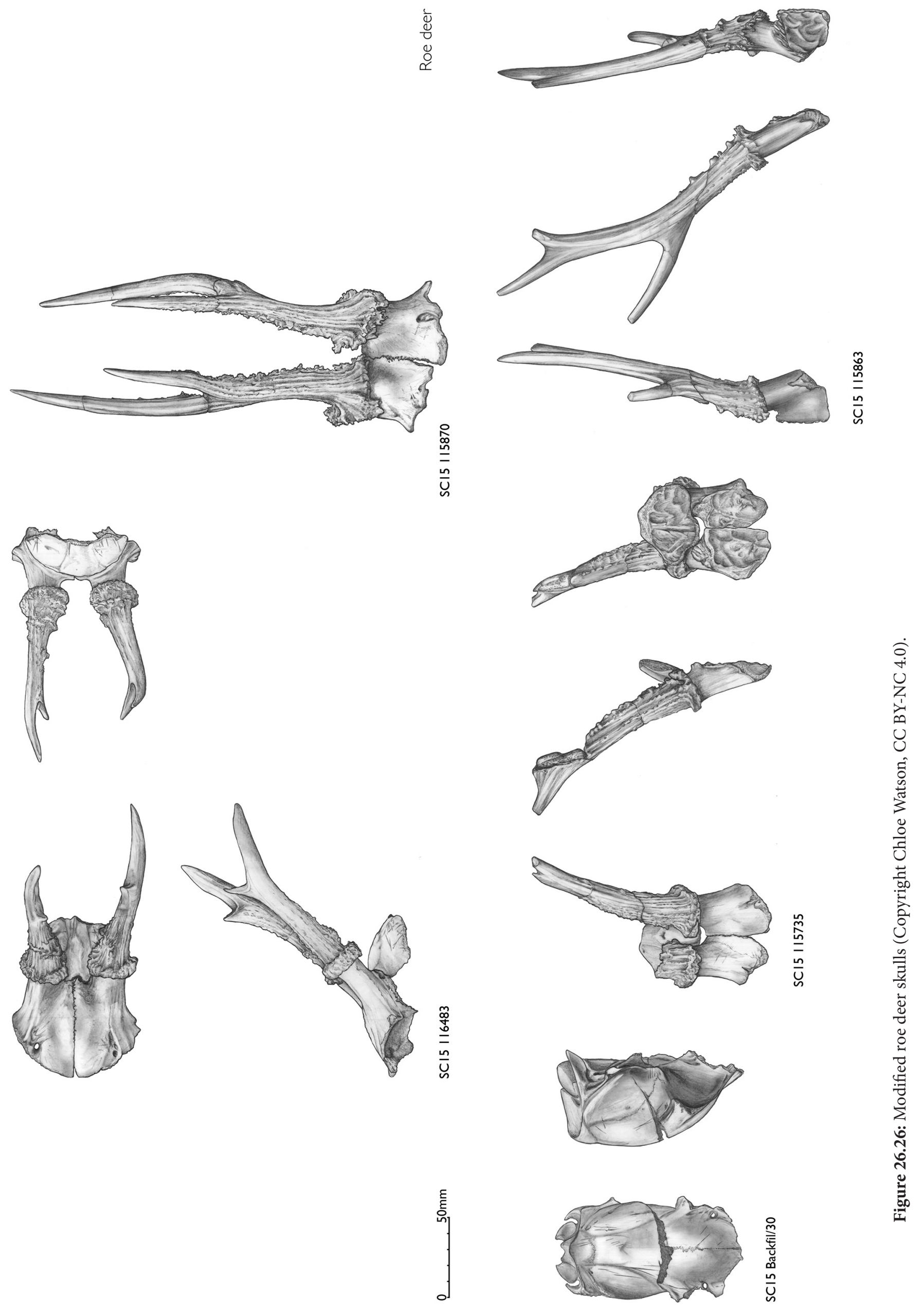




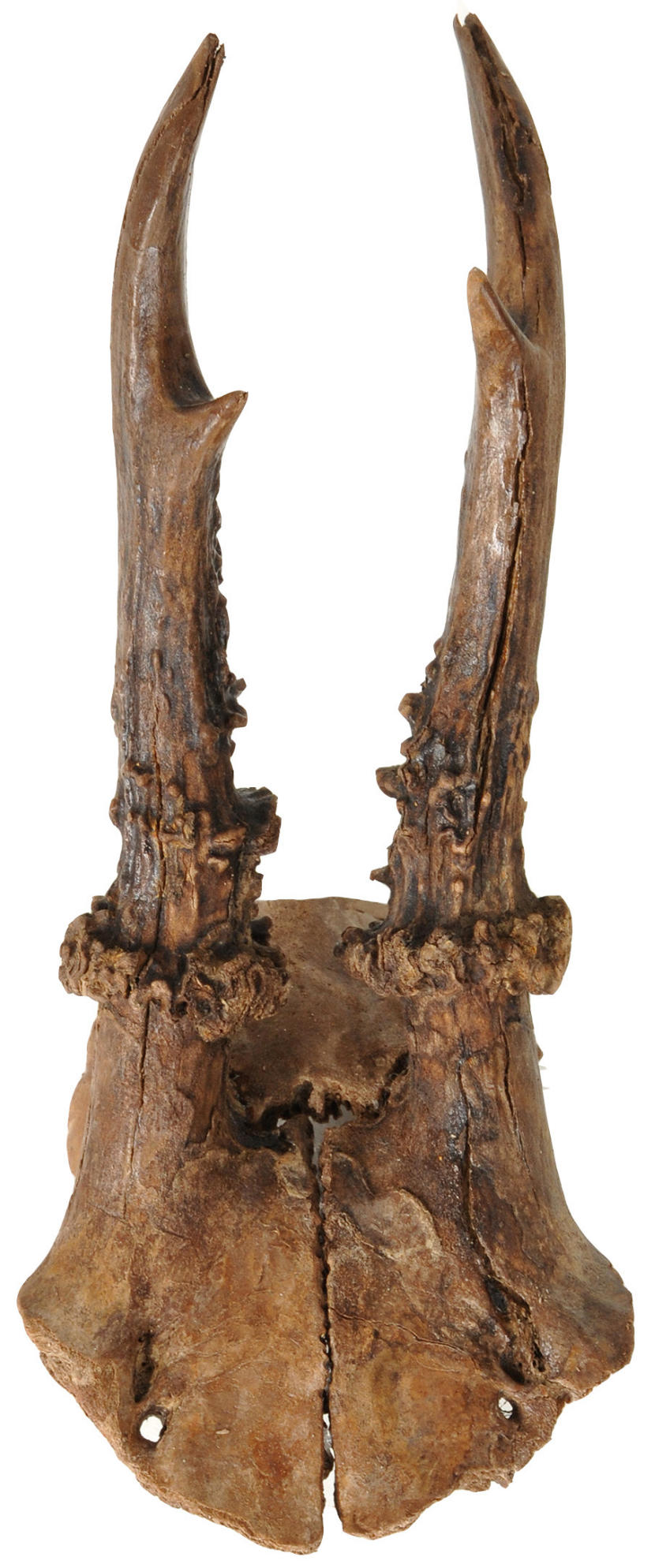

0 Centimetres

Figure 26.27: Roe deer crania $<116483>$ (Photograph taken by Paul Shields. Copyright University of York, CC BY-NC 4.0. Model created by Neil Gevaux. Copyright Star Carr Project CC BY-NC 4.0).

To view this interactive model, scan the QR code with your mobile device or visit DOI: https://doi.org/10.22599/book2.2

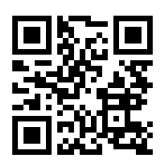


However, in comparison to the red deer crania the preservation of the roe deer crania is markedly poor, preventing the direct identification of working marks. As such, the evidence for human modification of these pieces is scarce, and there is also more variation within the portion of the braincase retained. There are differences in size between the red deer frontlets and roe deer crania which suggest that they could not have functioned in precisely the same ways, with the roe deer skull and braincase being considerably smaller and more curved than that of a red deer. So as these similarities cannot be positively demonstrated on typological or technological grounds, it remains a tentative link based on anatomical similarities. Yet their concentration around Clark's area and proximity to the locus of frontlet deposition, as well as the elements retained in their deposited form, suggest that there may be some links between these materials. As such, the roe deer crania may be considered to be associated with the same patterns of deposition as the red deer frontlets, and share some formal similarities which may suggest some overlap in meanings, without going so far as to say that they should be considered as the same type of artefact.

\section{The European context}

The similarities between the Star Carr frontlets and similar modified red deer crania from Northern Germany were noted by Clark (1954) in his original publication. Since then, further examples of mooted modified red deer crania have been added to this list of associated material (Wild 2014), notably including the discovery of two examples of similar artefacts at Bedburg-Königshoven (Street 1991) (see Chapter 12). In his comprehensive review of the wider body of data, Wild has provided a clear typological definition for these artefacts (termed Hirschgeweihkappen, or stag antler cap), which is reproduced here (Wild 2014, 158):

1. frontal, parietal and interparietal bones are always present,

2. antlers, frontal and parietal bones are only partially preserved,

3. a minimum of $75 \%$ of the different bones of the skull (including the antlers) show modifications by humans,

4. temporal, parietal and interparietal bones show two artificial perforations. In case one of these shows signs of breakage another perforation was usually nicked or cut into the bone,

5. antler beams and tines are longitudinally split and are often shortened.

The use of this definition helps to refine our understanding of these artefacts, restricting their chronological range to the Preboreal and eliminating much of the formal variation within this group to a small number of morphologically similar artefacts from Star Carr, Bedburg-Königshoven, Berlin-Biesdorf and Hohen Viecheln (Wild 2014). However, the specificity within this typological framework creates some problems when attempting to account for variation within the group. For instance, the Bedburg-Königshoven artefacts have little if any working of the antlers and feature much more of the nasal bones than are represented on any of the Star Carr frontlets (Chapter 12). The impact that this has on the form of the finished artefact has been noted by Conneller (2011), and there remains confusion over whether the Bedburg-Königshoven frontlets are 'finished' (Street and Wild 2015), and thus not technically Hirschgeweihkappen, or 'unfinished' Hirschgeweihkappen (Wild 2014). Further to this, the definition rules out many of the artefacts originally identified by Clark as frontlets, based on their lack of perforations or the fact that they are only represented by one side of the skull. In the case of our finds, despite the similarities in form, working methods, and distinction from the other cranial faunal remains excavated which are described above, only one artefact, $<103695>$, would be classed as a Hirschgeweihkappen, as all others lack perforations.

The data and analysis presented above allows for an alternative approach to this problem. With good contextual control, a robust chronological model, and a relatively large data set to work with, Star Carr allows for a technological approach to defining this group of artefacts (Little et al. 2016). Many of these factors are absent at other sites in Europe, and so shift analysis towards more typological approaches (e.g. Wild 2014). This is unavoidable, and indeed, where technological analysis is inhibited by preservation conditions and contextual data lacking, a typological approach remains an excellent way to interrogate this challenging dataset.

Taking a technological approach allows for artefacts which are formally varied (such as individuals which lacked antlers prior to working, lack perforations, or are unfinished) to be considered together in terms of the 
similarities in their treatment and the specific working techniques that have been used in their production. From this perspective, parallels can be seen with the Bedburg-Königshoven examples, in the character and location of defleshing and deskinning marks, and use of pecking to create perforations for instance (Street and Wild 2015). This is despite the formal differences between the artefacts from these sites, and irrespective of their finished or unfinished nature.

Certain frontlets from the recent Star Carr finds show specific similarities with artefacts from within the Hirschgeweihkappen group. For instance, $<115876>$ has very strong parallels in form to I/82/26 from Berlin-Biesdorf, in the form of the antlers retained and the bones of the skull represented. Beyond this, several other of the recent Star Carr finds have similarities with artefacts categorised within the Schlachtausschuss (butchery discard) typological group. These artefacts also feature modified crania but lack perforations, often have had the antlers heavily reduced or totally removed, and feature a much smaller portion of the frontal bone than is seen on the Hirschgeweihkappen. The heavily reduced nature of the antlers, and area of the frontal bones that has been broken away on $<99528>$ and $<114937>$ is similar to that observed on HV.3412 from Hohen Viecheln. The shed nature of the antlers and elements of cranial bones retained on $\langle 116020\rangle,\langle 116601\rangle$ and $<116888>$ is similar to K127 from Friesack 4 (Wild 2014).

\section{Interpretation}

The initial dichotomised interpretations offered by Clark as to the frontlets' purpose have characterised their discussion for the vast majority of the latter 20th century as either a shamanic headdress or a hunting disguise. More recently, however, Conneller has critiqued this dichotomy, noting that many hunter-gatherer worldviews afford little meaningful distinction between functional and symbolic actions (Conneller 2004). It can be argued that as shamans are widely regarded as playing a key role in negotiating human/animal relations and hunting luck, an artefact which aids the corporeal transformation of a human body into that of a deer could be used in both capacities interchangeably. Certainly, the contexts into which the frontlets were being deposited at Star Carr suggests a complex set of meanings were attached to them, being deposited alongside a range of other unusual material cultures which had been prepared for deposition through dehafting, and forming part of such a persistent practice within a changing environment across the site. In particular, the concentration of frontlets in association with such an intense period of animal body processing and consumption within Clark's area may have imbued their production, use and deposition with an entangled set of meanings.

Zvelebil (1993) argues that the most robust ethnographic parallels for the hunter-gatherer groups of Northern Europe can be found in modern day Siberia, an area from which Clark drew his original analogies with the shamanic dress of the Evenki, documented by Witsen in the 17th century (Figure 26.18). Interestingly, the ethnographic examples of the use of deer heads in hunting disguises (Moyne de Morgues 1875; Gifford 1936; Du Bois 1936; Strachey 1953; Lawson 1967; Wetmore 1975) for stalking originate exclusively from North America, and this practice is not widely documented amongst the hunter-gatherers of Siberia. Following on from this, it may be tentatively suggested that the ethnographic data indicates that the Star Carr frontlets are more likely to have formed part of a shamanic costume, rather than to have been used as a hunting disguise.

A further point in relation to ethnographic and anthropological analogy concerns the terminology associated with the frontlets. Few of the writers who describe hunting disguises and shamanic dress use the term 'headdress' directly. Instead, 'mask' is often the term used to describe various forms of ceremonial dress and now has a considerable body of anthropological theory associated with it (Ray 1967; Lévi-Strauss 1982; Fienup-Riordan 1987; Oosten 1992; Pollock 1995; Humphrey and Onon 1996; Edson 2005; Vitebsky 2006; Pedersen 2011). Within an anthropological context, a mask can be taken to be any object which temporarily alters the identity of the wearer, and is not necessarily assumed to be worn directly over the face (Pernet 1992). Finger, knee, pocket, chest and crown masks are all documented within the First Nations cultures of Pacific Coast North America (Oosten 1992). There is ongoing uncertainty over precisely how the Star Carr frontlets may have been worn (Street and Wild 2015), with any attached hide or fur components (such as strapping, padding, insulation or decoration) either being removed prior to deposition, or failing to preserve within the peat deposits. As such, the ambiguity of the term 'mask' seems appropriate for the frontlets within this context.

Many anthropological studies of masks highlight the rich formal variation present within ethnographic collections, and the important role that form can play in the meaning and use of the masks themselves within 


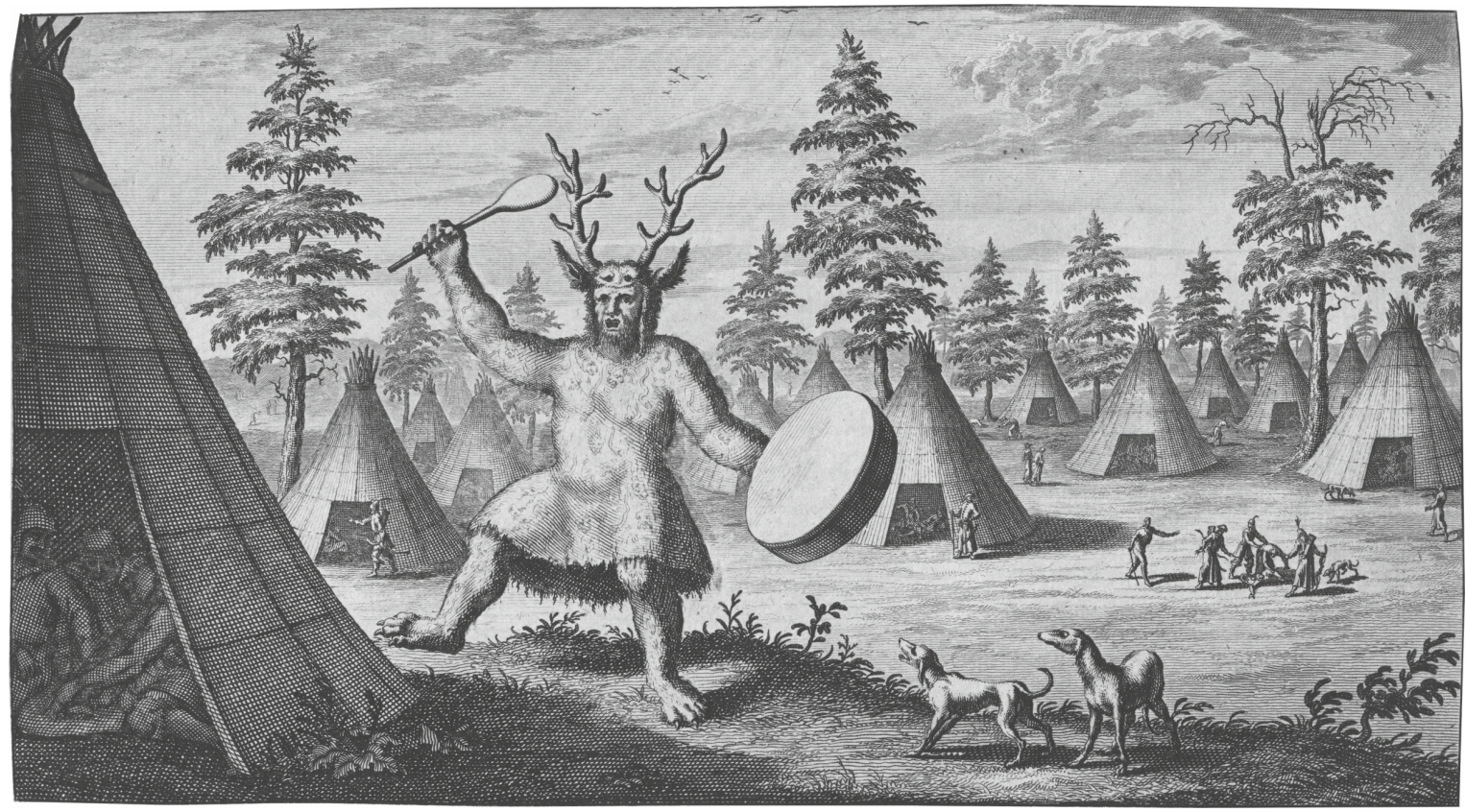

Figure 26.28: Depiction of a Tungus shaman wearing deer headdress (Witsen and Boddaert 1705).

communal ceremonies. Vitebsky cites an example of shamanic masks in Siberia. He describes Evenki shaman, who are known to adjust the form of antlers used within their costumes by sharpening their tips, in order to make them more 'spear-like'. This enhances their ability to negotiate and, if need be, fight with spirits encountered on different levels of the sky when in a trance state (Vitebsky 2006).

When considered in relation to the Star Carr frontlets, using the term 'mask' may be fruitful as a means to understanding the formal variation across the finished artefacts, with variations in the occurrence of perforations, the numbers of perforations on a single artefact, the presence of antlers, and the extent to which antlers were reduced, and the form of a female skull. It is possible that this formal variation may be associated with change through time, yet the range of frontlet forms represented within Clark's area, a single phase of the site's occupation, would suggest that these different styles of frontlet are contemporary. By considering the frontlets as masks, we could interpret this variation as attempts to evoke specific types of deer identity and facilitate specific kinds of negotiation.

As such, masks of male deer with shed antlers, male deer with severely reduced antlers, adult female deer and male deer with antlers which mimic the form of young stags would give the wearer the ability to create specific identities appropriate for negotiating with other beings. Whilst a direct analogy here should be avoided, due to the potential for masks as composite artefacts to incorporate the materials and forms which reference other types of being, this range of frontlet forms does suggest considerable diversity in the number of distinct identities, and potential forms of beings, within the cosmology of the inhabitants of Star Carr.

Considering the Star Carr frontlets as masks also helps to frame further questions concerning their broader social context. In his seminal essay on mask theory, Pizzorno (2010) defines a series of core philosophical concepts which are challenged by the physical form, display and wearing of masks. These include the materiality of masks as objects, which have been argued to be key vehicles of transformation and thus markers of liminality (Thomassen 2014). Pizzorno highlights the concept of looking through masks, across this liminal zone. Complex layers of meanings can be attached to masks through their material choices, which directly affect what a wearer might be looking into. This imbues masks with a social potentiality, and as such their display can be as powerful as their actual wearing.

The static facial expressions of masks have strong implications for death, mimicking the faces of the dead. This is brought into sharp focus when placed over the faces of the living. As such, masks have the potential to blur the distinctions between life and death. The unmoving and timeless character of expression, coupled with 
these life/death connotations, can also evoke concepts of ancestry and myth, allowing a wearer to enact and engage with mythologies. This again is furthered by the way in which a mask wearer can become a 'monster'-a composite being in themselves, whose face does not match their body. As such, this manipulation of identity, and the construction of identities which would not have otherwise be possible, is a key element of mask wearing.

Conversely, Pizzorno also describes the strong association between mask wearing and dance and notes choreography, rhythm and lighting as a way of animating mask expressions beyond this stasis. This dynamism in mask wearing is furthered by the action of donning and removing masks. These acts allow the wearer to control the timings of shifts in identity within the context of a performance. These performances, again, can be linked to the narrative of mythology, but also have an effect on both the audience and performers. Pizzorno notes the inherent terror of watching masks being worn: the concealment of the face and the implications of transformation creating a fundamental tension over what is being revealed and what is concealed. In the words of Canetti $(1984,376)$, 'I am exactly what you see, and everything that you fear is behind me'. This element of fear and horror again imbues the performance and performer with further power over the audience.

In sum, the discussion provided here serves to highlight the diversity of new research avenues and lines of enquiry which the term 'mask' opens for considering the Star Carr modified deer crania. To engage further with the issues raised here, a contextual approach is necessary; one which considers the broader processes and characteristics of the social context of human life at Star Carr. This draws from multiple strands of the archaeological and palaeoenvironmental record and is provided within Chapter 10.

\section{Conclusions}

This chapter has presented the first analysis of 12 red deer frontlet artefacts from Star Carr, which supplements the 21 excavated by Clark and broaden this category of artefact considerably. These appear to have been deposited at various points within the site's occupational history, and into a range of different environments. The area excavated by Clark appears to be a particular focus for frontlet deposition, but smaller quantities were deposited within the detrital wood scatter, the eastern timber platform and higher up the slope of the lake edge within peat-forming environments. There appears to be no change in form across this period of time, either in terms of typology or technology, although the range of forms narrows as the quantity of artefacts deposited decreases. Away from Clark's area, the deposition of frontlets into other spatial and environmental contexts at the site suggests a dynamic persistence of depositional practices. Whilst the forms of the artefacts being deposited at the site, within the detrital wood scatter and higher peat forming environments are much less varied than those in Clark's area, they demonstrate a level of continuity (both before and after the deposition in Clark's area) in some underlying aspects of the cosmology of the inhabitants of Star Carr, throughout the duration of its occupation.

There is considerable formal variation within this material, which, as with the barbed points (see Chapter 25), creates problems for applying a rigorous and informative typological analysis. As an alternative, given the size of this dataset, we advocate a technological approach to their definition, which allows similarities in châine opératoire to be emphasized for an otherwise diverse group of artefacts.

In interpreting these artefacts we have noted the arguments of Zvelebil (1993) over the suitability of ethnographic analogies for the Mesolithic of Northern Europe. As such, it can be shown that the societies of circumpolar Eurasia are rarely (if ever) known to use deer skulls as disguises for hunting. In contrast, there are several accounts on the use of animal skulls in the creation of masks and costumes. The evidence for using deer heads as hunting disguises is plentiful amongst hunter-gatherer groups but appears to be heavily focussed in North America. In the absence of more direct evidence, we argue that the critical application of ethnographic analogy suggests that these artefacts were most likely used in dance and ceremonial contexts.

In a similar vein, it can also be seen that the terminology used to define these artefacts is problematic. The term frontlet draws heavily on the anatomical features of the artefact, and suggests confusion with elements of a faunal assemblage. Equally, the ongoing uncertainty over precisely how (and if) these artefacts might have been worn on the body presents problems for the term headdresses. As an alternative, the term 'mask' might be better applied within this context. This establishes links to the rich history of ethnographic and anthropological research into the use of masks in a range of cultural contexts. The broad definition of masks within this literature also leaves the question of precisely how they might have been worn open to debate. 